\title{
TU/e EmonOWEN

\section{Stable Fe/ZSM-5 nanosheet zeolite catalysts for the oxidation of benzene to phenol}

\section{Citation for published version (APA):}

Meng, L., Zhu, X., \& Hensen, E. J. M. (2017). Stable Fe/ZSM-5 nanosheet zeolite catalysts for the oxidation of benzene to phenol. ACS Catalysis, 7(4), 2709-2719. https://doi.org/10.1021/acscatal.6b03512

\section{Document license:}

CC BY-NC-ND

DOI:

10.1021/acscatal.6b03512

Document status and date:

Published: 07/04/2017

\section{Document Version:}

Publisher's PDF, also known as Version of Record (includes final page, issue and volume numbers)

\section{Please check the document version of this publication:}

- A submitted manuscript is the version of the article upon submission and before peer-review. There can be important differences between the submitted version and the official published version of record. People interested in the research are advised to contact the author for the final version of the publication, or visit the $\mathrm{DOI}$ to the publisher's website.

- The final author version and the galley proof are versions of the publication after peer review.

- The final published version features the final layout of the paper including the volume, issue and page numbers.

Link to publication

\section{General rights}

Copyright and moral rights for the publications made accessible in the public portal are retained by the authors and/or other copyright owners and it is a condition of accessing publications that users recognise and abide by the legal requirements associated with these rights.

- Users may download and print one copy of any publication from the public portal for the purpose of private study or research.

- You may not further distribute the material or use it for any profit-making activity or commercial gain

- You may freely distribute the URL identifying the publication in the public portal.

If the publication is distributed under the terms of Article 25fa of the Dutch Copyright Act, indicated by the "Taverne" license above, please follow below link for the End User Agreement:

www.tue.nl/taverne

Take down policy

If you believe that this document breaches copyright please contact us at:

openaccess@tue.nl

providing details and we will investigate your claim. 


\title{
Stable Fe/ZSM-5 Nanosheet Zeolite Catalysts for the Oxidation of Benzene to Phenol
}

\author{
Lingqian Meng, Xiaochun Zhu, and Emiel J. M. Hensen*๑ \\ Inorganic Materials Chemistry, Schuit Institute of Catalysis, Department of Chemical Engineering and Chemistry, Eindhoven \\ University of Technology, P.O. Box 513, 5600 MB, Eindhoven, The Netherlands
}

Supporting Information

ABSTRACT: Fe/ZSM-5 nanosheet zeolites of varying thickness were synthesized with di- and tetraquaternary ammonium structure directing agents and extensively characterized for their textural, structural, and catalytic properties. Introduction of $\mathrm{Fe}^{3+}$ ions in the framework of nanosheet zeolites was slightly less effective than in bulk ZSM-5 zeolite. Steaming was necessary to activate all catalysts for $\mathrm{N}_{2} \mathrm{O}$ decomposition and benzene oxidation. The higher the Fe content, the higher the degree of Fe aggregation was after catalyst activation. The degree of Fe aggregation was lower when the crystal domain size of the zeolite or the Fe content was decreased. These two parameters had a substantial influence on the catalytic performance. Decreasing the number of $\mathrm{Fe}$ sites along the $b$-direction strongly suppressed secondary reactions of phenol and, accordingly, catalyst

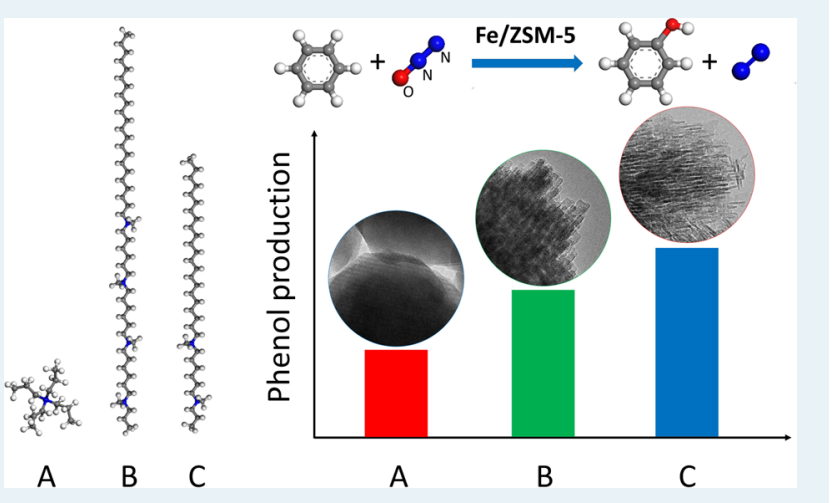
deactivation. This together with the absence of diffusional limitations in nanosheet zeolites explains the much higher phenol productivity obtainable with nanostructured Fe/ZSM-5. Steamed Fe/ZSM-5 zeolite nanosheet synthesized using $\mathrm{C}_{22-6-3} \cdot \mathrm{Br}_{2}$ (domain size in $b$-direction $\sim 3 \mathrm{~nm}$ ) and containing $0.24 \mathrm{wt} \% \mathrm{Fe}$ exhibited the highest catalytic performance. During the first 24 $\mathrm{h}$ on stream, this catalyst produced $185 \mathrm{mmol}_{\text {phenol }} \mathrm{g}^{-1}$. Calcination to remove the coke deposits completely restored the initial activity.

KEYWORDS: Fe/ZSM-5, nanosheet, benzene oxidation, deactivation, Fe content

\section{INTRODUCTION}

Phenol is an important industrial precursor for the production of various polymers such as nylon and phenolic resins, drugs, herbicides, and detergents. ${ }^{1}$ In industrial practice, phenol is obtained from benzene via the three-step cumene process. This process is environmentally stressing, and its economics are disadvantaged by the coproduction of equimolar amounts of acetone. ${ }^{2,3}$ Substantial efforts have been made to develop more attractive one-step routes for phenol manufacture. ${ }^{2-7}$ Panov and co-workers found that Fe/ZSM-5 zeolite catalyzes the oxidation of benzene to phenol using nitrous oxide as oxidant. ${ }^{6,8-10} \mathrm{~N}_{2} \mathrm{O}$ can for instance be obtained from waste streams in nitric acid and adipic acid plants. ${ }^{11}$ Although not commercialized, this approach constitutes an interesting alternative to the cumene process.

The mechanism of the benzene oxidation to phenol reaction with Fe/ZSM-5 zeolite catalysts involves two steps: ${ }^{10}$

$$
\begin{aligned}
& \mathrm{N}_{2} \mathrm{O}+()_{\alpha} \rightarrow(\mathrm{O})_{\alpha}+\mathrm{N}_{2} \\
& \mathrm{C}_{6} \mathrm{H}_{6}+(\mathrm{O})_{\alpha} \rightarrow()_{\alpha}+\mathrm{C}_{6} \mathrm{H}_{6} \mathrm{O}
\end{aligned}
$$

$\mathrm{N}_{2} \mathrm{O}$ decomposition proceeds on active iron centers (" $\alpha$-sites") to form a surface oxygen species that is often called " $\alpha$-oxygen"; " $\alpha$-oxygen" is able to oxidize benzene to phenol. Although the exact structure of the " $\alpha$-sites" in Fe/ZSM-5 zeolites for $\mathrm{N}_{2} \mathrm{O}$ decomposition and oxidation of benzene to phenol remains unclear, most studies agree that on the role of cationic extraframework Fe complexes in Fe/ZSM-5 zeolites. ${ }^{9,12-17}$ It has been found that only a fraction of these " $\alpha$-oxygen" are able to oxidize benzene to phenol. ${ }^{5,15}$ Steaming of isomorphously substituted Fe/ZSM-5 zeolite is crucial to enhance the number of extraframework $\mathrm{Fe}$ ions. ${ }^{9,18}$ During steaming, $\mathrm{Fe}-\mathrm{O}-\mathrm{Si}$ bonds in $\mathrm{Fe} / \mathrm{ZSM}-5$ crystals are broken, resulting in the migration of $\mathrm{Fe}$ from the zeolite framework to extraframework locations. In this process, a range of extraframework Fe species are usually formed including isolated $\mathrm{Fe}$ cations, oligomeric cationic Fe complexes, and neutral Fe-oxide clusters $\left(\mathrm{Fe}_{x} \mathrm{O}_{y}\right)$ as well as larger Fe-oxide aggregates. Bulk Fe-oxides species display very low activity in the decomposition of $\mathrm{N}_{2} \mathrm{O} .{ }^{16}$ There are strong indications that isolated $\mathrm{Fe}^{2+}$ sites are involved in the unusual oxidation chemistry of Fe/ZSM-5 zeolites. ${ }^{1}$ A recent DFT study by Li et al. confirmed that " $\alpha$-oxygen" obtained by $\mathrm{N}_{2} \mathrm{O}$ decomposition on isolated ferrous $\left(\mathrm{Fe}^{2+}\right)$ species can catalyze the oxidation of benzene to phenol. When " $\alpha$-oxygen"

Received: December 10, 2016

Revised: February 27, 2017

Published: March 10, 2017 
atoms are generated on isolated or oligomeric ferric $\left(\mathrm{Fe}^{3+}\right)$ oxide clusters, the oxidation of benzene to phenol results in formation of a phenolate intermediate, which is strongly adsorbed on the $\mathrm{Fe}$ sites and causes deactivation. This may explain why not all " $\alpha$-oxygen" is active in benzene oxidation. The strongly adsorbed phenolate intermediate has also been considered as a precursor of coke, contributing to pore plugging. ${ }^{19}$ These ideas are in keeping with earlier findings of Sachtler and co-workers. ${ }^{5}$ Another side-reaction involves the oxidation of phenol into dihydroxybenzenes and their condensation into high-molecular weight aromatic compounds, which slowly migrate through the micropores and may also deposit there. ${ }^{20}$ Brønsted acid sites in zeolite channels are believed to be another cause of coke formation in these $\mathrm{Fe} /$ ZSM-5 zeolites. ${ }^{5,20-22}$ All of these coking mechanisms will contribute to blocking of the zeolite micropores, explaining the relatively rapid deactivation of $\mathrm{Fe} / \mathrm{ZSM}-5$ catalysts in benzene oxidation. It is important to mention that ion exchange of ZSM-5 with Fe-salts in various ways results in poor catalysts for benzene oxidation with nitrous oxide, ${ }^{13,23}$ mainly because of the more extensive agglomeration of iron. ${ }^{12}$

Besides the high price of nitrous oxide, rapid deactivation of $\mathrm{Fe} / \mathrm{ZSM}-5$ catalysts is a serious challenge in realizing a commercial process for the direct oxidation of benzene using nitrous oxide. Catalyst stability can be improved by decreasing mass transfer limitations imposed by the micropore system of Fe/ZSM-5 zeolite. These limitations are caused by the long intracrystalline pathways that molecules have to traverse in pores of similar size as reactant and product molecules. Various strategies have been employed to achieve increased mass transport such as synthesizing zeolites with extra-large micropores, $^{24}$ introducing intracrystalline mesopores in zeolite particles and reducing the zeolite crystal size. ${ }^{25-27}$ Using diquaternary ammonium structure directing agents (SDAs), Ryoo and co-workers successfully synthesized ZSM-5 zeolites with a sheet-like structure with a size in the $b$-direction of MFI zeolite limited to several unit cell dimensions. ${ }^{28,29}$ By varying the number of ammonium groups in the hydrophilic headgroup, the thickness of such ZSM-5 zeolite nanosheets can be controlled. $^{30}$ Using a similar diquaternary ammonium SDA, Koekkoek et al. synthesized for the first time Fe/ZSM-5 zeolite nanosheets. ${ }^{1}$ When applied in benzene oxidation, such $\mathrm{Fe} /$ ZSM-5 nanosheet zeolites were found to exhibit higher catalytic activity and longevity than conventional bulk Fe/ZSM-5 zeolites. As these initial synthesis efforts were hampered by several issues related to the use of the $\mathrm{SDA}^{31}$ it was not possible to draw meaningful conclusions on the influence of the Fe content and crystal size for these promising nanosheet zeolites as catalysts for the oxidation of benzene to phenol. The main starting point of the present study was to explore the hypothesis that consecutive reactions of phenol can be suppressed by (i) lowering the Fe content and (ii) decreasing the crystal thickness in the $b$-direction of MFI nanosheets. Therefore, in this work, we prepared a set of Fe/ZSM-5 zeolite nanosheets with varying $\mathrm{Fe}$ content by hydrothermal synthesis. The thickness of zeolite nanosheets was controlled by using diand tetraquaternary ammonium SDAs $\left[\mathrm{C}_{22} \mathrm{H}_{45}-\mathrm{N}^{+}\left(\mathrm{CH}_{3}\right)_{2^{-}}\right.$ $\left.\mathrm{C}_{6} \mathrm{H}_{12}-\mathrm{N}^{+}\left(\mathrm{CH}_{3}\right)_{2}-\mathrm{C}_{3} \mathrm{H}_{7}\right] \mathrm{Br}_{2}$ and $\left[\mathrm{C}_{22} \mathrm{H}_{45}-\mathrm{N}^{+}\left(\mathrm{CH}_{3}\right)_{2}-\mathrm{C}_{6} \mathrm{H}_{12^{-}}\right.$ $\left.\mathrm{N}^{+}\left(\mathrm{CH}_{3}\right)_{2}-\mathrm{C}_{6} \mathrm{H}_{12}-\mathrm{N}^{+}\left(\mathrm{CH}_{3}\right)_{2}-\mathrm{C}_{6} \mathrm{H}_{12}-\mathrm{N}^{+}\left(\mathrm{CH}_{3}\right)_{2}-\mathrm{C}_{3} \mathrm{H}_{7}\right] \mathrm{Br}_{4}$. Compared to our earlier work, ${ }^{1}$ these SDAs are terminated on the short-chain side by a propyl group, which facilitates crystallization of the structure. ${ }^{31}$ The structural and textural properties of these materials were characterized in detail by elemental analysis, transmission electron microscopy (TEM), X-ray diffraction (XRD), Ar porosimetry, and diffusereflectance UV-vis (DR-UV-vis) and UV Raman spectroscopy. The catalytic performance in the oxidation of benzene to phenol was investigated for these Fe/ZSM-5 zeolite nanosheets and their bulk counterparts. The results are discussed with emphasis on catalyst activity and stability as a function of nanoscale dimensions of the zeolites.

\section{EXPERIMENTAL SECTION}

Synthesis of SDAs. $\left[\mathrm{C}_{22} \mathrm{H}_{45^{-}}-\mathrm{N}^{+}\left(\mathrm{CH}_{3}\right)_{2}-\mathrm{C}_{6} \mathrm{H}_{12}-\mathrm{N}^{+}\left(\mathrm{CH}_{3}\right)_{2^{-}}\right.$ $\left.\mathrm{C}_{3} \mathrm{H}_{7}\right] \mathrm{Br}_{2}$ (denoted as $\left.\mathrm{C}_{22-6-3} \cdot \mathrm{Br}_{2}\right): 3.9 \mathrm{~g}(0.01 \mathrm{~mol}$ ) 1-bromodococane (TCI, 98\%) was dissolved in $50 \mathrm{~mL}$ of toluene (Biosolve, 99.5\%) and added dropwise into a $50 \mathrm{~mL}$ solution of $21.4 \mathrm{~mL}(0.1 \mathrm{~mol})$ of $N, N, N^{\prime} N^{\prime}$-tetramethyl-1,6-diaminohexane (Aldrich, 99\%) in ethanol (Biosolve, 99.8\%). The solution was refluxed in an oil bath at $343 \mathrm{~K}$ for $12 \mathrm{~h}$. After cooling to room temperature, the solution was kept at $277 \mathrm{~K}$ for $1 \mathrm{~h}$, then filtered and washed with diethyl ether (Biosolve, 99.5\%). The resulting solid product $\mathrm{N}$-(6-(dimethylamino)hexyl)-N,N-dimethyldocosan-1-aminium bromide (denoted as $\mathrm{C}_{22-6} \cdot \mathrm{Br}$ ) was dried in a vacuum oven at $323 \mathrm{~K}$ overnight. This intermediate was subsequently reacted with $4.92 \mathrm{~g}(0.04 \mathrm{~mol})$ 1bromopropane (Aldrich, 99\%) in ethanol at $343 \mathrm{~K}$ for $12 \mathrm{~h}$. The resulting solution was cooled in a refrigerator at $277 \mathrm{~K}$ for $1 \mathrm{~h}$, then filtered, washed with diethyl ether, and dried in a vacuum oven at $323 \mathrm{~K}$. The product was $\mathrm{C}_{22-6-3} \cdot \mathrm{Br}_{2}$.

$\left[\mathrm{C}_{22} \mathrm{H}_{45}-\mathrm{N}^{+}\left(\mathrm{CH}_{3}\right)_{2}-\mathrm{C}_{6} \mathrm{H}_{12}-\mathrm{N}^{+}\left(\mathrm{CH}_{3}\right)_{2}-\mathrm{C}_{6} \mathrm{H}_{12}-\mathrm{N}^{+}\left(\mathrm{CH}_{3}\right)_{2}-\right.$ $\left.\mathrm{C}_{6} \mathrm{H}_{12}-\mathrm{N}^{+}\left(\mathrm{CH}_{3}\right)_{2}-\mathrm{C}_{3} \mathrm{H}_{7}\right] \mathrm{Br}_{4}$ (denoted as $\left.\mathrm{C}_{22-6-6-6-3} \cdot \mathrm{Br}_{4}\right): 5.62 \mathrm{~g}$ $(0.01 \mathrm{~mol})$ of $\mathrm{C}_{22-6} \cdot \mathrm{Br}$ and $24.4 \mathrm{~g}(0.1 \mathrm{~mol})$ of 1,6dibromohexane (Aldrich, 96\%) were dissolved in $50 \mathrm{~mL}$ ethanol and stirred at $323 \mathrm{~K}$ for $24 \mathrm{~h}$. After cooling to room temperature, the solution was kept at $277 \mathrm{~K}$ for $1 \mathrm{~h}$, then filtered and washed with diethyl ether. The resulting solid product $\left[\mathrm{C}_{22} \mathrm{H}_{45}-\mathrm{N}^{+}\left(\mathrm{CH}_{3}\right)_{2}-\mathrm{C}_{6} \mathrm{H}_{12}-\mathrm{N}^{+}\left(\mathrm{CH}_{3}\right)_{2}-\mathrm{C}_{6} \mathrm{H}_{12}-\mathrm{Br}\right] \mathrm{Br}_{2}$

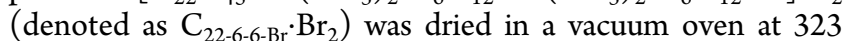
$\mathrm{K}$ overnight. The intermediate $\mathrm{C}_{22-6-6-\mathrm{Br}} \cdot \mathrm{Br}_{2}$ and $21.4 \mathrm{~mL}(0.1$ mol) $N, N, N^{\prime} N^{\prime}$-tetramethyl-1,6-diaminohexane were dissolved in $50 \mathrm{~mL}$ of ethanol and refluxed at $343 \mathrm{~K}$ for $12 \mathrm{~h}$. After cooling at $277 \mathrm{~K}$ for $1 \mathrm{~h}$, the solution was filtered and washed with diethyl ether, and the white intermediate $\left[\mathrm{C}_{22} \mathrm{H}_{45^{-}}\right.$ $\mathrm{N}^{+}\left(\mathrm{CH}_{3}\right)_{2}-\mathrm{C}_{6} \mathrm{H}_{12}-\mathrm{N}^{+}\left(\mathrm{CH}_{3}\right)_{2}-\mathrm{C}_{6} \mathrm{H}_{12}-\mathrm{N}^{+}\left(\mathrm{CH}_{3}\right)_{2}-\mathrm{C}_{6} \mathrm{H}_{12}-\mathrm{N}-$ $\left.\left(\mathrm{CH}_{3}\right)_{2}\right] \mathrm{Br}_{3}$ (denoted as $\mathrm{C}_{22-6-6-6-0} \cdot \mathrm{Br}_{3}$ ) was dried in a vacuum oven at $323 \mathrm{~K}$ overnight. The compound $\mathrm{C}_{22-6-6-6-0} \cdot \mathrm{Br}_{3}$ was reacted with $4.92 \mathrm{~g}(0.04 \mathrm{~mol})$ of 1-bromopropane at $343 \mathrm{~K}$ in $50 \mathrm{~mL}$ of ethanol for $12 \mathrm{~h}$. Afterward, the liquid mixture was cooled at $277 \mathrm{~K}$ for $1 \mathrm{~h}$. The solid product was filtered and washed with diethyl ether, then dried in a vacuum oven at 323 $\mathrm{K}$ for $12 \mathrm{~h}$. The final product was $\mathrm{C}_{22-6-6-6-3} \cdot \mathrm{Br}_{4}$.

Synthesis of Zeolites. Fe/ZSM-5 zeolite nanosheets were synthesized using $\mathrm{C}_{22-6-3} \cdot \mathrm{Br}_{2}$ and $\mathrm{C}_{22-6-6-6-3} \cdot \mathrm{Br}_{4}$ as SDAs. In a typical synthesis, $\mathrm{NaOH}$ (Merck, 99\%) and SDA were dissolved in demi-water at $333 \mathrm{~K}$ for $1 \mathrm{~h}$. After cooling to room temperature, a second solution which was made by mixing tetraethylorthosilicate (TEOS, Merck, 99\%), aluminum nitrate nonahydrate (Aldrich, reagent grade), iron nitrate nonahydrate (Aldrich, reagent grade), and demi-water was added under vigorous stirring. The molar ratio of the gel compositions was as follows: $22 \mathrm{NaOH}: 2.5 \mathrm{Al}\left(\mathrm{NO}_{3}\right)_{3} \cdot 9 \mathrm{H}_{2} \mathrm{O}: 100 \mathrm{SiO}_{2}: 7.5$ $\mathrm{C}_{22-6-3} \cdot \mathrm{Br}_{2}$ (or $\left.3.25 \mathrm{C}_{22-6-6-6-3} \cdot \mathrm{Br}_{4}\right): x \mathrm{Fe}\left(\mathrm{NO}_{3}\right)_{3} \cdot 9 \mathrm{H}_{2} \mathrm{O}(x=$ $0.556,0.278$, or 0.139$)$ : $4000 \mathrm{H}_{2} \mathrm{O}$. After stirring for $1 \mathrm{~h}$, the resultant gel was transferred into a Teflon-lined autoclave and heated under rotating $(60 \mathrm{rpm})$ at $423 \mathrm{~K}$ for $9-25$ days. 
Table 1. Details about the Synthesis of Bulk and Sheet-Like Fe/ZSM-5 Catalysts

\begin{tabular}{|c|c|c|c|c|c|c|c|c|c|}
\hline \multirow[b]{2}{*}{ zeolite } & \multirow[b]{2}{*}{ SDA } & \multicolumn{6}{|c|}{ gel composition (molar ratio) } & \multirow[b]{2}{*}{$T(\mathrm{~K})$} & \multirow[b]{2}{*}{ time (days) } \\
\hline & & SDA & TEOS & $\mathrm{Al}\left(\mathrm{NO}_{3}\right)_{3}$ & $\mathrm{NaOH}$ & $\mathrm{Fe}\left(\mathrm{NO}_{3}\right)_{3}$ & $\mathrm{H}_{2} \mathrm{O}$ & & \\
\hline Fe/ZSM-5(TPA,180) & TPAOH & 30 & 100 & 2.5 & - & 0.556 & 4500 & 443 & 5 \\
\hline $\mathrm{Fe} / \mathrm{ZSM}-5(\mathrm{TPA}, 360)$ & TPAOH & 30 & 100 & 2.5 & - & 0.278 & 4500 & 443 & 5 \\
\hline $\mathrm{Fe} / \mathrm{ZSM}-5(\mathrm{TPA}, 720)$ & TPAOH & 30 & 100 & 2.5 & - & 0.139 & 4500 & 443 & 5 \\
\hline $\mathrm{Fe} / \mathrm{ZSM}-5(2 \mathrm{~N}, 180)$ & $\mathrm{C}_{22-6-3} \cdot \mathrm{Br}_{2}$ & 7.5 & 100 & 2.5 & 22 & 0.556 & 4000 & 423 & 9 \\
\hline $\mathrm{Fe} / \mathrm{ZSM}-5(2 \mathrm{~N}, 360)$ & $\mathrm{C}_{22-6-3} \cdot \mathrm{Br}_{2}$ & 7.5 & 100 & 2.5 & 22 & 0.278 & 4000 & 423 & 9 \\
\hline $\mathrm{Fe} / \mathrm{ZSM}-5(2 \mathrm{~N}, 720)$ & $\mathrm{C}_{22-6-3} \cdot \mathrm{Br}_{2}$ & 7.5 & 100 & 2.5 & 22 & 0.139 & 4000 & 423 & 9 \\
\hline $\mathrm{Fe} / \mathrm{ZSM}-5(4 \mathrm{~N}, 180)$ & $\mathrm{C}_{22-6-6-6-3} \cdot \mathrm{Br}_{4}$ & 3.25 & 100 & 2.5 & 22 & 0.556 & 4000 & 423 & 25 \\
\hline $\mathrm{Fe} / \mathrm{ZSM}-5(4 \mathrm{~N}, 360)$ & $\mathrm{C}_{22-6-6-6-3} \cdot \mathrm{Br}_{4}$ & 3.25 & 100 & 2.5 & 22 & 0.278 & 4000 & 423 & 15 \\
\hline $\mathrm{Fe} / \mathrm{ZSM}-5(4 \mathrm{~N}, 720)$ & $\mathrm{C}_{22-6-6-6-3} \cdot \mathrm{Br}_{4}$ & 3.25 & 100 & 2.5 & 22 & 0.139 & 4000 & 423 & 15 \\
\hline
\end{tabular}

For the synthesis of bulk Fe/ZSM-5 catalysts, TEOS and tetrapropylammonium hydroxide (TPAOH, Merck, 40\%) were mixed with demi-water and added dropwise into the solution which was made by dissolving aluminum nitrate nonahydrate and iron nitrate nonahydrate in demi-water. The molar ratio of the gel compositions was as follows: $2.5 \mathrm{Al}\left(\mathrm{NO}_{3}\right)_{3} \cdot 9 \mathrm{H}_{2} \mathrm{O}: 100$ $\mathrm{SiO}_{2}: 30$ TPAOH: $x \mathrm{Fe}\left(\mathrm{NO}_{3}\right) \cdot 9 \mathrm{H}_{2} \mathrm{O}(x=0.556,0.278$, or 0.139 ): $4500 \mathrm{H}_{2} \mathrm{O}$. After vigorous stirring at room temperature for $1 \mathrm{~h}$, the resulting gel was transferred to a Teflon-lined autoclave and crystallized statically at $448 \mathrm{~K}$ for 5 days.

After crystallization, the products were filtered, washed with copious amounts of demi-water, and dried overnight at $383 \mathrm{~K}$. The zeolites were calcined at $823 \mathrm{~K}$ for $10 \mathrm{~h}$ under flowing air. The calcined zeolites were ion-exchanged three times with $1 \mathrm{M}$ $\mathrm{NH}_{4} \mathrm{NO}_{3}$ solution followed by calcination at $823 \mathrm{~K}$ for $4 \mathrm{~h}$ under flowing air in order to obtain their proton forms. The nanosheet zeolites are denoted as Fe/ZSM-5 $(x \mathrm{~N}, y)$ with $x$ the number of quaternary ammonium ions in templates (2 or 4) and $y$ the $\mathrm{Si} / \mathrm{Fe}$ ratio in synthesis gel $(180,360$, or 720$)$. The bulk zeolites are denoted as Fe/ZSM-5(TPA, $y$ ) with $y$ the Si/ Fe ratio $(180,360$, or 720$)$ in synthesis gel.

Steaming activation was carried out by heating the samples in a flow of $10 \%$ water vapor in artificial air $\left(100 \mathrm{~mL} \mathrm{~min} \mathrm{~min}^{-1}\right)$ at $973 \mathrm{~K}$ for $3 \mathrm{~h}$. The steamed samples are denoted by using the suffix "-st". The details of the syntheses procedure are collected in Table 1.

Catalyst Characterization. The elemental composition of the catalysts was determined by inductively coupled plasma optical emission spectrometry (ICP-OES). To extract metals, samples were dissolved in a mixture of $\mathrm{HF} / \mathrm{HNO}_{3} / \mathrm{H}_{2} \mathrm{O}$ (1:1:1).

DR-UV-vis spectra were recorded on a Shimadzu UV-2401 PC spectrometer in diffuse-reflectance mode with a $60 \mathrm{~mm}$ integrating sphere. $\mathrm{BaSO}_{4}$ was used as the reference. The spectra were transformed into the Kubelka-Munk function.

UV Raman spectra were recorded with a Jobin-Yvon T64000 triple stage spectrograph with spectral resolution of $2 \mathrm{~cm}^{-1}$. The laser line at $244 \mathrm{~nm}$ of a Lexel 95-SHG laser was used as the exciting source with an output of $20 \mathrm{~mW}$. The power of the laser at the sample was about $2 \mathrm{~mW}$.

XRD patterns were recorded on a Bruker D4 Endeavor powder diffraction system using $\mathrm{Cu} \mathrm{K} \alpha$ radiation with a scanning speed of $2.4^{\circ} \mathrm{min}^{-1}$ in the range of $5-60^{\circ}$.

TEM images were taken on a FEI Tecnai 20 at an electron acceleration voltage of $200 \mathrm{kV}$. Prior to measurement, the catalysts were suspended in ethanol and dispersed over a $\mathrm{Cu}$ grid with a holey carbon film.

Surface area and porosity of zeolites were determined by $\mathrm{Ar}$ physisorption in static mode at $87 \mathrm{~K}$ on a Micromeritics ASAP
2020 instrument. The samples were outgassed at $723 \mathrm{~K}$ for $8 \mathrm{~h}$ prior to the sorption measurements. The Brunauer-EmmettTeller (BET) surface area of ZSM-5 zeolite was determined in the relative pressure range $\left(p / p_{0}\right) 0.05-0.25$. The total pore volume was calculated at $p / p_{0}=0.97$. The micropore (pores $<1.0 \mathrm{~nm}$ ) and supermicropore (pores in the range of 1.0-2.0 $\mathrm{nm}$ ) volumes of sheet-like Fe/ZSM-5 zeolites were determined by the NLDFT method (Ar at $87 \mathrm{~K}$ assuming slit pores without regularization). The micropore volume of bulk Fe/ZSM-5 zeolites was determined by the $t$-plot method via the Broekhoff-de Boer model in the thickness range of 0.34$0.50 \mathrm{~nm}$. The mesopore volume and pore size distribution were determined from the adsorption branch of the isotherm using the NLDFT method.

Quantification of Active Fe Sites. The amount of active sites (" $\alpha$-sites") in the catalyst was determined by titration of the catalyst with $\mathrm{N}_{2} \mathrm{O}$ gas at $523 \mathrm{~K}$. In a typical procedure, 100 $\mathrm{mg}$ of catalyst (sieve fraction $125-250 \mu \mathrm{m}$ ) was placed in a stainless-steel microreactor. Prior to testing, the catalyst was calcined in $\mathrm{He}\left(140 \mathrm{~mL} \mathrm{~min}{ }^{-1}\right)$ from 298 to $823 \mathrm{~K}$ at a ramp rate of $2 \mathrm{~K} \mathrm{~min}^{-1}$, followed by an isothermal period of $1 \mathrm{~h}$. After cooling the sample to $523 \mathrm{~K}$ in $\mathrm{He}\left(140 \mathrm{~mL} \mathrm{~min}^{-1}\right)$, the $\mathrm{He}$ flow was switched to a reactant flow with the composition $1.03 \% \mathrm{Ar}$ and $0.98 \% \mathrm{~N}_{2} \mathrm{O}$ in $\mathrm{He}$ gas at a total flow rate $140 \mathrm{~mL}$ $\mathrm{min}^{-1}$. Argon served as an inert tracer. A well-calibrated mass spectrometer was used to determine the amount of $\mathrm{N}_{2}$ in the reactor effluent.

Catalytic Activity Measurements. The catalytic activity of the Fe/ZSM-5 zeolites in the oxidation of benzene to phenol using $\mathrm{N}_{2} \mathrm{O}$ as oxidant was determined in a tubular fixed-bed reactor with $4 \mathrm{~mm}$ inner diameter. Typically, an amount of 100 mg of catalyst, which was pressed and sieved into $125-250 \mu \mathrm{m}$ particles, was loaded into a quartz tube. Prior to reaction, the catalyst was calcined in artificial air $\left(100 \mathrm{~mL} \mathrm{~min}^{-1}\right)$ to $823 \mathrm{~K}$ at a ramp rate of $2 \mathrm{~K} \mathrm{~min}^{-1}$ followed by an isothermal period of 2 h. After cooling to $623 \mathrm{~K}$ in artificial air, the catalyst was exposed to the reaction feed mixture which consists of 1 vol \% of benzene and $4 \mathrm{vol} \%$ of $\mathrm{N}_{2} \mathrm{O}$ in $\mathrm{He}$ at a total flow rate of 100 $\mathrm{mL} \mathrm{min}^{-1}$. The weight hourly space velocity (WHSV) was 1.89 $\mathrm{g} \mathrm{g}^{-1} \mathrm{~h}^{-1}$. We also evaluated the catalytic performance of the best performing catalyst against its bulk counterpart in excess benzene conditions. For this purpose, the catalyst was exposed to a reaction feed mixture of 5 vol \% of benzene and 0.5 vol \%

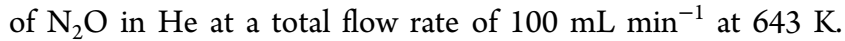
The WHSV was $9.45 \mathrm{~g} \mathrm{~g}^{-1} \mathrm{~h}^{-1}$. The reactor effluent was analyzed by gas chromatography (Hewlett-Packard GC-5890 equipped with an HP-5 column and a flame ionization detector) and a Balzers-Pfeiffer quadrupole mass spectrometer. The coke content of the spent catalyst after a reaction time of 
$24 \mathrm{~h}$ was determined by thermogravimetric analysis (TGA) on a TGA/DSC 1 STAR system of Mettler Toledo. The temperature was increased from 298 to $1273 \mathrm{~K}$ with a ramping rate $10 \mathrm{~K} \mathrm{~min}^{-1}$ under flowing artificial air at a rate of $50 \mathrm{~mL}$ $\min ^{-1}$.

\section{RESULTS AND DISCUSSION}

Structural Characterization. The XRD patterns of the calcined and steamed Fe/ZSM-5 samples are collected in Figure 1 and Figure S1. All zeolites have the MFI framework
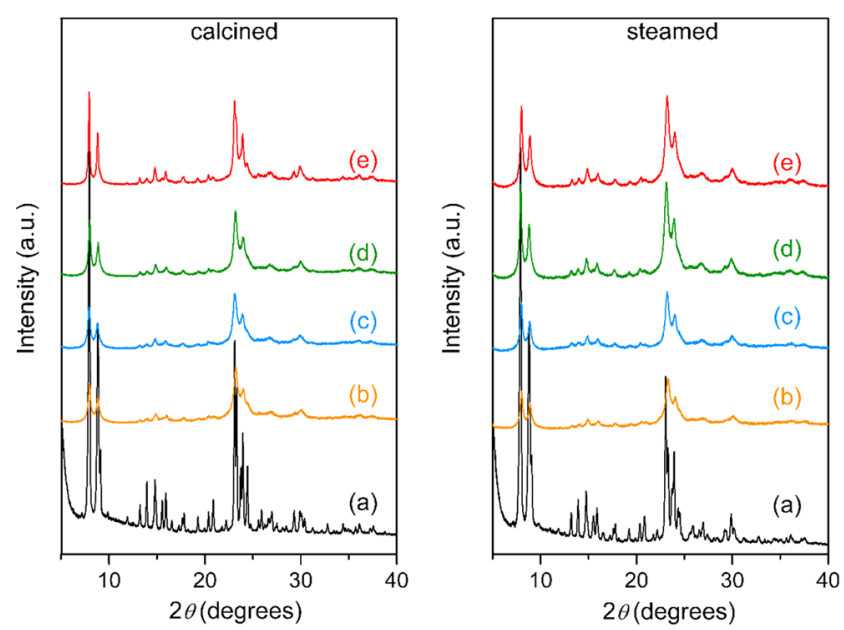

Figure 1. X-ray powder diffraction patterns of calcined (left) and steamed (right) zeolites. (a) Fe/ZSM-5(TPA,360), (b) Fe/ZSM5(4N,360), (c) Fe/ZSM-5(2N,180), (d) Fe/ZSM-5(2N,360), and (e) $\mathrm{Fe} / \mathrm{ZSM}-5(2 \mathrm{~N}, 720)$.

topology. ${ }^{1}$ No features belonging to large iron oxide particles were observed, which is indicative for the high Fe dispersion in the as-synthesized zeolites. Different from bulk zeolite, only the $h 0 l$ reflections in the XRD patterns of the nanosheet Fe/ZSM-5 zeolites were sufficiently sharp for indexing. The absence or strong broadening of the $0 k 0$ reflections is due to the very small size of the zeolite in the $b$-direction (i.e., the direction of the straight channels in zeolites with the MFI topology). The XRD patterns of the steamed samples are similar to those of the calcined parent ones, which demonstrates the good hydrothermal stability of bulk and nanosheet Fe/ZSM-5 zeolites.
The elemental compositions of the zeolites as determined by ICP elemental analysis are listed in Table 2 . All of the zeolites have a similar $\mathrm{Si} / \mathrm{Al}$ atomic ratio close to $40 . \mathrm{Si} / \mathrm{Fe}$ ratios of 180,360 , and 720 in the synthesis gel led to zeolites with $\mathrm{Si} / \mathrm{Fe}$ ratios around 180,360 , and $770-850$, respectively. Thus, nearly all $\mathrm{Al}$ and $\mathrm{Fe}$ ions present in the synthesis gel were built into the Fe/ZSM-5 zeolites. Steaming did not alter the elemental composition of the samples.

Figure 2 and Figure S2 display the Ar physisorption isotherms and pore size distribution of bulk and nanosheet
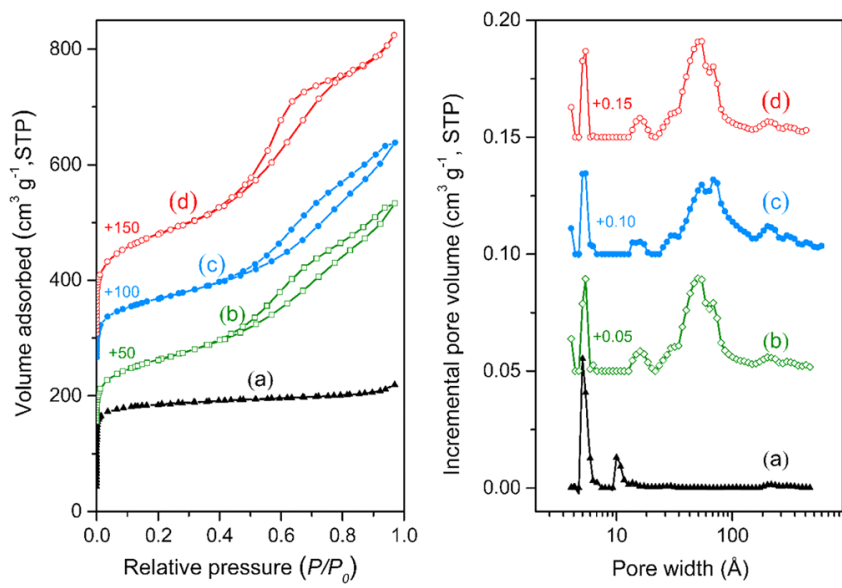

Figure 2. Ar physisorption isotherms (left) and pore size distribution (right) of Fe/ZSM-5 zeolites. (a) Fe/ZSM-5(TPA,360)-st, (b) Fe/ ZSM-5(2N,360), (c) Fe/ZSM-5(2N,360)-st, and (d) Fe/ZSM$5(4 \mathrm{~N}, 360)$-st. The isotherms were vertically offset by equal intervals of $50 \mathrm{~cm}^{3} \mathrm{~g}^{-1}$. The pore size distributions were calculated using the NLDFT method using the adsorption branch and vertically offset by equal intervals of $0.05 \mathrm{~cm}^{3} \mathrm{~g}^{-1}$.

Fe/ZSM-5 zeolites. The strong uptake at low $p / p_{0}$ confirms the presence of micropores. Typically, the Fe/ZSM-5 nanosheet zeolites show a gradual uptake over the $p / p_{0}$ range $0.4-0.9$ with a H4 hysteresis loop, which is characteristic for materials that contain mesopores. Pore size distribution data demonstrate that the nanosheet zeolites contain a large amount of mesopores with a wide distribution. For all bulk zeolites, the mesopore volume is very small. These mesopores originate from voids between the zeolite crystals.

\section{Table 2. Composition and Textural Properties of Fe/ZSM-5 Catalysts}

\begin{tabular}{|c|c|c|c|c|c|c|c|c|c|}
\hline catalyst & $\begin{array}{l}\mathrm{Al} \text { content } \\
(\%)^{a}\end{array}$ & $\begin{array}{l}\mathrm{Fe} \text { content } \\
(\%)^{a}\end{array}$ & $\begin{array}{l}\mathrm{Si} / \\
\mathrm{Al}\end{array}$ & $\mathrm{Si} / \mathrm{Fe}$ & $\begin{array}{c}S_{\mathrm{BET}}^{b} \\
\left(\mathrm{~m}^{2} \mathrm{~g}^{-1}\right)\end{array}$ & $\begin{array}{c}V_{\text {total }}{ }^{c} \\
\left(\mathrm{~cm}^{3} \mathrm{~g}^{-1}\right)\end{array}$ & $\begin{array}{c}V_{\text {meso }}^{d} \\
\left(\mathrm{~cm}^{3} \mathrm{~g}^{-1}\right)\end{array}$ & $\begin{array}{l}V_{\text {supermicro }} \\
\left(\mathrm{cm}^{3} \mathrm{~g}^{-1}\right)\end{array}$ & $\begin{array}{c}V_{\text {micro }} f \\
\left(\mathrm{~cm}^{3} \mathrm{~g}^{-1}\right)\end{array}$ \\
\hline Fe/ZSM-5(TPA,180)-st & 1.13 & 0.51 & 39 & 180 & 418 & 0.22 & 0.05 & 0.011 & 0.13 \\
\hline Fe/ZSM-5(TPA,360)-st & 1.17 & 0.25 & 38 & 364 & 415 & 0.21 & 0.04 & 0.008 & 0.15 \\
\hline Fe/ZSM-5(TPA,720)-st & 1.16 & 0.12 & 38 & 771 & 423 & 0.22 & 0.04 & 0.008 & 0.13 \\
\hline $\mathrm{Fe} / \mathrm{ZSM}-5(2 \mathrm{~N}, 180)$-st & 1.08 & 0.50 & 41 & 180 & 475 & 0.59 & 0.36 & 0.007 & 0.13 \\
\hline $\mathrm{Fe} / \mathrm{ZSM}-5(2 \mathrm{~N}, 360)$-st & 1.07 & 0.24 & 41 & 381 & 472 & 0.49 & 0.38 & 0.003 & 0.12 \\
\hline $\mathrm{Fe} / \mathrm{ZSM}-5(2 \mathrm{~N}, 720)$-st & 0.99 & 0.11 & 44 & 843 & 423 & 0.47 & 0.33 & 0.000 & 0.15 \\
\hline $\mathrm{Fe} / \mathrm{ZSM}-5(4 \mathrm{~N}, 180)$-st & 1.06 & 0.46 & 41 & 198 & 470 & 0.43 & 0.28 & 0.010 & 0.17 \\
\hline $\mathrm{Fe} / \mathrm{ZSM}-5(4 \mathrm{~N}, 360)$-st & 1.05 & 0.25 & 42 & 367 & 516 & 0.61 & 0.47 & 0.002 & 0.13 \\
\hline $\mathrm{Fe} / \mathrm{ZSM}-5(4 \mathrm{~N}, 720)$-st & 1.00 & 0.12 & 44 & 783 & 540 & 0.54 & 0.38 & 0.007 & 0.17 \\
\hline $\mathrm{Fe} / \mathrm{ZSM}-5(2 \mathrm{~N}, 360)$ & 0.24 & 0.24 & 41 & 381 & 479 & 0.54 & 0.32 & 0.004 & 0.13 \\
\hline
\end{tabular}

${ }^{a}$ Determined using ICP-OES analysis. ${ }^{b}$ BET surface area $\left(p / p_{0}=0.05-0.25\right) .{ }^{c}$ Total pore volume at $p / p_{0}=0.97 .{ }^{d}$ Mesopore volume calculated by the NLDFT method using the adsorption branch of the isotherm. ${ }^{e}$ Supermicropore volume defined as pores in the range $1.0-2.0 \mathrm{~nm}$, determined by the NLDFT method. ${ }^{f}$ Micropore volume of bulk Fe/ZSM-5 was determined by $t$-plot method via the Broekhoff-de Boer model in the thickness range $0.34-0.50 \mathrm{~nm}$. Micropore $(<1.0 \mathrm{~nm})$ volume of sheet Fe/ZSM-5 was determined by the NLDFT method. 
The corresponding textural properties of these zeolites are listed in Table 2. The BET surface area, the total pore volume, and the mesopore volume of the nanosheet zeolites are significantly higher than those of bulk Fe/ZSM-5 zeolites. The micropore volume of the bulk zeolites is higher than that of nanosheet zeolites. For nanosheet zeolites, the BET surface area reached value as high as $540 \mathrm{~m}^{2} \mathrm{~g}^{-1}$, and the largest total pore volume was $0.61 \mathrm{~cm}^{3} \mathrm{~g}^{-1}$, which is much higher than the micropore volume of bulk Fe/ZSM-5 zeolite. Mesopores contribute significantly to the total pore volume of the nanosheet zeolites. It is interesting to note the relatively small difference in textural properties between calcined and steamed $\mathrm{Fe} / \mathrm{ZSM}-5(2 \mathrm{~N}, 360)$, underpinning further the very good hydrothermal stability of the nanosheet zeolites.

Figure 3 shows representative TEM images of the Fe/ZSM-5 zeolites prepared at a $\mathrm{Si} / \mathrm{Fe}$ of 360 . It is clear that all of the

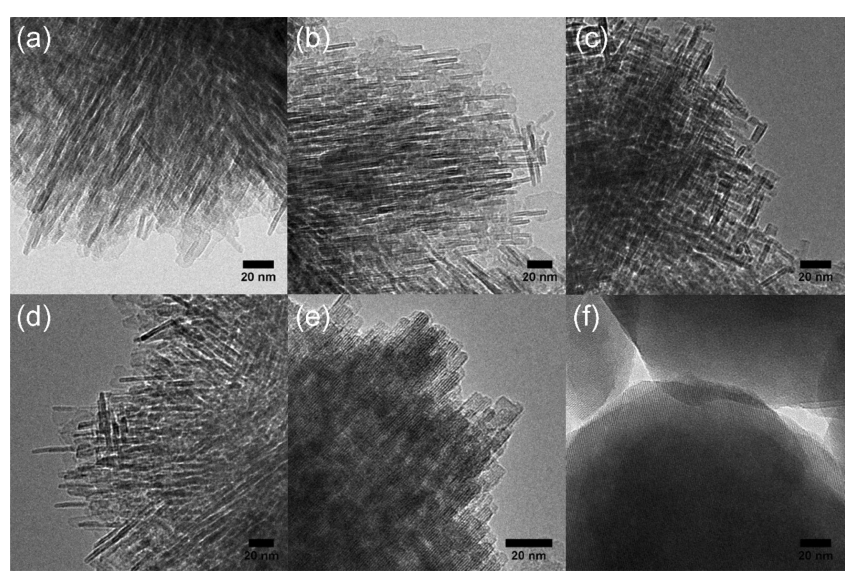

Figure 3. Representative TEM images of (a) Fe/ZSM-5(2N,180)-st, (b) Fe/ZSM-5(2N,360)-st, (c) Fe/ZSM-5(2N,720)-st, (d) Fe/ZSM$5(2 \mathrm{~N}, 360),(\mathrm{e}) \mathrm{Fe} / \mathrm{ZSM}-5(4 \mathrm{~N}, 360)$-st, and (f) Fe/ZSM-5(TPA,360)st.

nanosheet zeolites contain quite narrow $a-c$ planes. The samples synthesized using the diquaternary ammonium SDA $\mathrm{C}_{22-6-3} \cdot \mathrm{Br}_{2}$ consist of uniform unilamellar nanosheets with a thickness of around $3 \mathrm{~nm}$. Considering that MFI's unit cell dimension in the $b$-direction of $1.974 \mathrm{~nm},{ }^{28,29}$ the nanosheet zeolites are about 1.5 unit cells thick in this direction. There is no significant difference in morphology among the nanosheets with different $\mathrm{Fe}$ content (Figure $3 \mathrm{a}-\mathrm{c}$ ). Consistent with the $\mathrm{XRD}$ and Ar physisorption results, TEM images of Fe/ZSM$5(2 \mathrm{~N}, 360)$ before and after steaming show similar morphology and texture. The nanosheet zeolites synthesized by SDA $\mathrm{C}_{22-6-6-6-3} \cdot \mathrm{Br}_{4}$ (Figure $3 \mathrm{e}$ ) are less uniform in terms of thickness in the $b$-direction. The on-average $\sim 6-8 \mathrm{~nm}$ thickness in the $b$ direction of these nanosheets corresponds to about 3-4 unit cells. The bulk zeolite (Figure $3 \mathrm{f}$ ) consists of large spherical particles with several hundreds of nanometers as reported before. $^{27}$

DRUV-vis and UV Raman Spectroscopy. The coordination state and extent of aggregation of $\mathrm{Fe}^{3+}$ in Fe/ZSM-5 zeolites were investigated by DR-UV-vis spectroscopy. The UV-vis spectra of the calcined and steamed zeolites are shown in Figure 4. The spectra of the calcined zeolites are dominated by two characteristic oxygen-to-metal charge-transfer bands around 211 and $245 \mathrm{~nm}$, which are related to $\mathrm{Fe}^{3+}$ at isolated tetrahedral framework sites. ${ }^{32-34}$ Thus, we conclude that $\mathrm{Fe}^{3+}$ is predominantly built into the zeolite framework by isomorphous substitution of $\mathrm{Si}^{4+}$ by $\mathrm{Fe}^{3+}$. The charge-transfer band around $275 \mathrm{~nm}$ is typical for highly dispersed octahedral Fe species. ${ }^{33}$ Compared to bulk zeolite, the calcined nanosheet zeolites contain already a certain fraction of highly dispersed extraframework Fe atoms. This difference points to a less rigid coordination around $\mathrm{Fe}$ atoms in sheet-like MFI zeolites compared with bulk zeolite. This may have to do with the location of part of the Fe sites near the surface of the zeolite nanosheets. Steaming results in extensive migration of tetrahedral $\mathrm{Fe}$ species from the crystal framework toward extraframework positions: oligomeric iron oxide clusters (333 $\mathrm{nm})$, larger $\mathrm{Fe}_{2} \mathrm{O}_{3}$-like aggregates $(427 \mathrm{~nm})$, and bulk $\mathrm{Fe}_{2} \mathrm{O}_{3}$ (545 nm) can be distinguished. ${ }^{1,34}$ Absent in bulk zeolite, a distinct shoulder around $275 \mathrm{~nm}$ in the spectra of steamed nanosheet zeolites confirms the presence of a larger fraction of highly dispersed Fe species inside the nanostructured materials. The nanosheet zeolites also contain a lower amount of $\mathrm{Fe}_{x} \mathrm{O}_{y}$ agglomerates. This is attributed to the small crystal size in the $b$-direction, which limits the agglomeration of Fe atoms during steaming. As expected, the degree of aggregation of Fe species
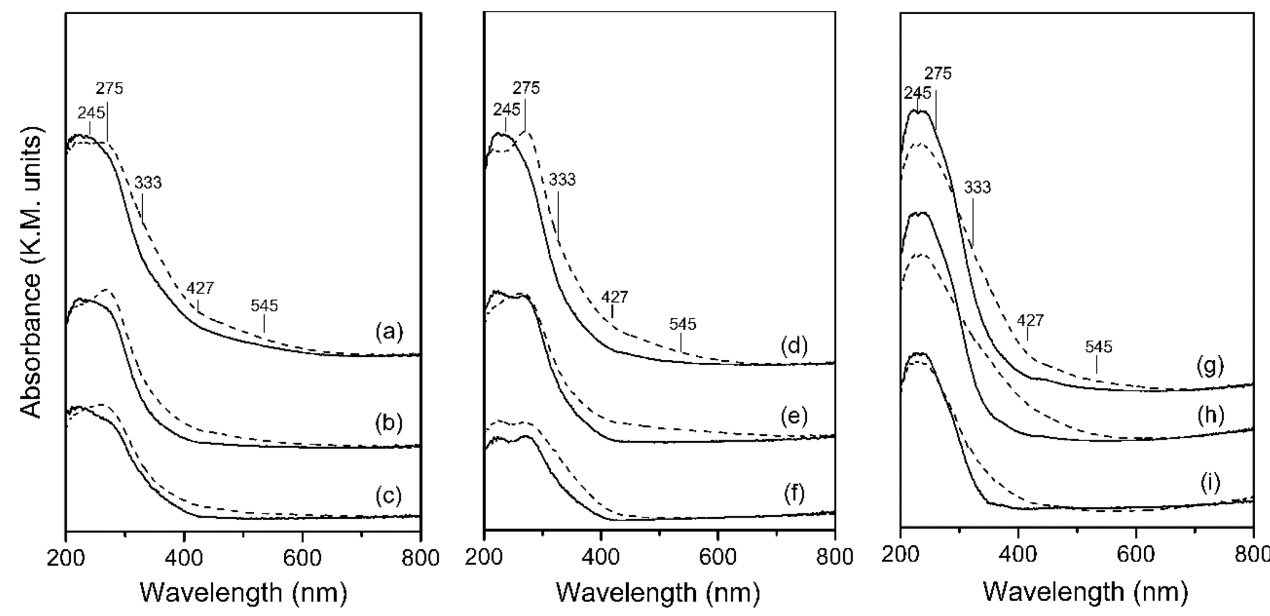

Figure 4. DR-UV-vis spectra of the calcined (full line) and steamed (dashed line) Fe/ZSM-5 zeolites. (a) Fe/ZSM-5(2N,180), (b) Fe/ZSM5(2N,360), (c) Fe/ZSM-5(2N,720), (d) Fe/ZSM-5(4N,180), (e) Fe/ZSM-5(4N,360), (f) Fe/ZSM-5(4N,720), (g) Fe/ZSM-5(TPA,180), (h) Fe/ ZSM-5(TPA,360), and (i) Fe/ZSM-5(TPA,720). 
tends to increase with $\mathrm{Fe}$ loading in both the bulk and nanosheet zeolites.

Figure 5 shows the UV Raman spectra (244 $\mathrm{nm}$ laser excitation) of calcined and steamed Fe/ZSM-5 zeolites. The
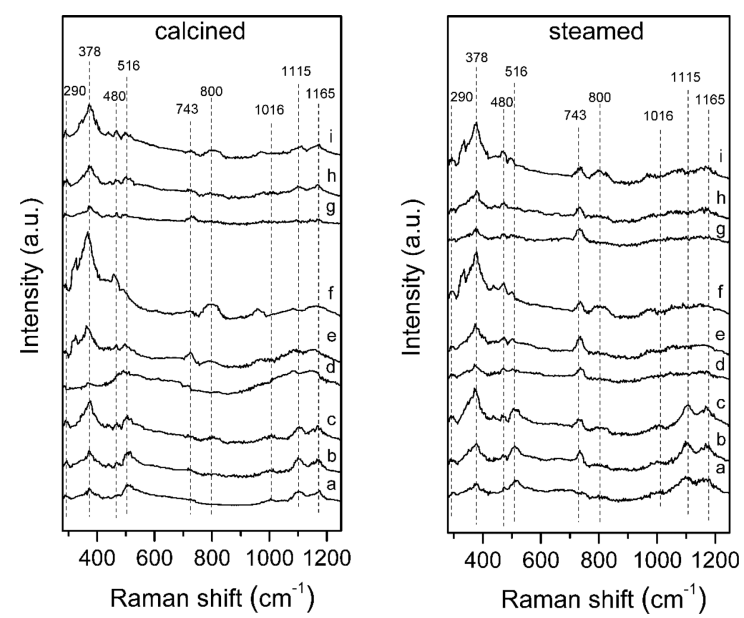

Figure 5. UV Raman spectra of the calcined and steamed Fe/ZSM-5 zeolites. (a) Fe/ZSM-5(TPA,180), (b) Fe/ZSM-5(TPA,360), (c) Fe/ ZSM-5(TPA,720), (d) Fe/ZSM-5(4N,180), (e) Fe/ZSM-5(4N,360), (f) $\mathrm{Fe} / \mathrm{ZSM}-5(4 \mathrm{~N}, 720)$, (g) Fe/ZSM-5(2N,180), (h) Fe/ZSM$5(2 \mathrm{~N}, 360)$, and (i) Fe/ZSM-5(2N, 720).

strong band at $378 \mathrm{~cm}^{-1}$ observed for all of the zeolites can be assigned to the characteristic double five-ring silica moiety in the MFI zeolite. ${ }^{33,35}$ Two more Raman bands at 480 and 800 $\mathrm{cm}^{-1}$ are also typical for the MFI structure. ${ }^{35}$ Upon steaming, these three peaks did not decrease in intensity, further confirming the good hydrothermal stability of the zeolites. The band at $516 \mathrm{~cm}^{-1}$ is due to the symmetric stretching/ bending vibrational modes of isolated $\mathrm{Fe}-\mathrm{O}-\mathrm{Si}$ species in the framework, while the bands at 1015,1115 , and $1165 \mathrm{~cm}^{-1}$ can be ascribed to the asymmetric $\mathrm{Fe}-\mathrm{O}-\mathrm{Si}$ stretching vibrational modes. $^{33,34}$ After steaming, these bands are substantially broadened or, in some cases, even absent. These changes can be explained by decreased framework $\mathrm{Fe}^{3+}$ content upon steaming due to $\mathrm{Fe}$ migration toward extraframework positions. Importantly, steaming results in increased intensity of the band at $743 \mathrm{~cm}^{-1}$, which has been related to active Fe centers for the oxidation of benzene to phenol in previous studies. ${ }^{1,33}$ The 743 $\mathrm{cm}^{-1}$ band is already visible in the spectra of the calcined zeolites. It is more prominent in the spectra of the calcined nanosheet Fe/ZSM-5 zeolites than in those of the calcined bulk zeolites. There are two possible reasons for this. First, it may be difficult to incorporate all of the $\mathrm{Fe}^{3+}$ ions in the zeolite framework of the nanosheets, and, accordingly, already some of the $\mathrm{Fe}$ ions end up at extraframework positions during zeolite synthesis. This is in line with the UV-vis data. The limited inclusion of heteroatoms in the framework of nanosheet zeolite has also been observed for $\mathrm{Al}^{3+} \cdot{ }^{36,37}$ Second, it may be that a larger part of the framework $\mathrm{Fe}^{3+}$ ions already migrate into extraframework positions during calcination of nanosheet zeolites. $^{1}$

Quantification of " $\boldsymbol{\alpha}$-Sites". $\mathrm{N}_{2} \mathrm{O}$ can be decomposed on " $\alpha$-sites" of Fe/ZSM-5 zeolites at $523 \mathrm{~K}$ by stoichiometric reaction $\mathrm{N}_{2} \mathrm{O}+()_{\alpha}=(\mathrm{O})_{\alpha}+\mathrm{N}_{2}$ (eq 1). Extraframework isolated $\mathrm{Fe}^{2+}$ and oligomeric $\mathrm{Fe}$ complexes are usually

Table 3. Concentration of " $\alpha$-Sites" ${ }^{a}$ and Catalytic Properties of Fe/ZSM-5 Zeolite Catalysts in the Oxidation of Benzene to Phenol $^{b}$

\begin{tabular}{|c|c|c|c|c|c|c|c|c|c|c|}
\hline catalyst & $\left.\begin{array}{c}\alpha \text {-sites } \\
(\mu \text { mol g } \\
-1\end{array}\right)$ & $\mathrm{X}_{5 \min { }^{c}}$ & $\begin{array}{c}\mathrm{S}_{5 \min }{ }^{c} \\
(\%)\end{array}$ & $\begin{array}{l}\mathrm{X}_{24 h}{ }^{d} \\
(\%)\end{array}$ & $\begin{array}{l}\mathrm{S}_{24}{ }^{d} \\
(\%)\end{array}$ & $\begin{array}{c}R_{\text {init }}^{e} \\
\left(\mathrm{mmol} \mathrm{g}^{-1} \mathrm{~h}^{-1}\right)\end{array}$ & $\begin{array}{c}R_{24 \mathrm{~h}^{f}}^{f} \\
\left(\mathrm{mmol} \mathrm{g}^{-1} \mathrm{~h}^{-1}\right)\end{array}$ & $\begin{array}{l}R_{24 \mathrm{~h}} / \\
R_{\text {init }}\end{array}$ & $\begin{array}{c}\text { yield }^{g} \\
\left(\mathrm{mmol} \mathrm{g}^{-1}\right)\end{array}$ & $\begin{array}{c}\text { coke }^{h} \\
\left(\mathrm{mg} \mathrm{g}^{-1}\right)\end{array}$ \\
\hline $\begin{array}{l}\mathrm{Fe} / \mathrm{ZSM}- \\
5(\mathrm{TPA}, 360)\end{array}$ & 0.5 & 19.9 & 65 & 4.9 & 51 & 3.2 & 0.6 & 0.19 & 26.9 & 53 \\
\hline $\mathrm{Fe} / \mathrm{ZSM}-5(2 \mathrm{~N}, 360)$ & 13.5 & 37.5 & 84 & 16.7 & 91 & 8.9 & 4.0 & 0.45 & 136.3 & 169 \\
\hline $\mathrm{Fe} / \mathrm{ZSM}-5(4 \mathrm{~N}, 360)$ & 5.8 & 38.5 & 84 & 12.6 & 60 & 8.4 & 2.0 & 0.24 & 78.3 & 155 \\
\hline $\begin{array}{l}\text { Fe/ZSM- } \\
5(\mathrm{TPA}, 180) \text {-st }\end{array}$ & 10.6 & 53.5 & 65 & 8.9 & 65 & 10.1 & 1.5 & 0.15 & 83.0 & 92 \\
\hline $\begin{array}{l}\mathrm{Fe} / \mathrm{ZSM}- \\
5(\mathrm{TPA}, 360) \text {-st }\end{array}$ & 4.9 & 34.5 & 84 & 8.5 & $>99$ & 8.1 & 2.0 & 0.26 & 85.8 & 84 \\
\hline $\begin{array}{l}\mathrm{Fe} / \mathrm{ZSM}- \\
5(\mathrm{TPA}, 720) \text {-st }\end{array}$ & 1.8 & 20.6 & 77 & 7.8 & 68 & 4.5 & 1.5 & 0.33 & 51.9 & 61 \\
\hline $\begin{array}{l}\mathrm{Fe} / \mathrm{ZSM}- \\
5(2 \mathrm{~N}, 180) \text {-st }\end{array}$ & 9.4 & 50.5 & 96 & 25.9 & 52 & 13.7 & 3.8 & 0.28 & 154.0 & 168 \\
\hline \multirow[t]{3}{*}{$\begin{array}{l}\mathrm{Fe} / \mathrm{ZSM}- \\
5(2 \mathrm{~N}, 360) \text {-st }\end{array}$} & 25.9 & 47.5 & 93 & 23.4 & $>99$ & 11.1 & 6.0 & 0.54 & 185.2 & 149 \\
\hline & & $47.3^{i}$ & $88^{i}$ & $30.0^{i}$ & $84^{i}$ & $10.5^{i}$ & $6.2^{i}$ & 0.60 & $181.5^{i}$ & \\
\hline & & $50.5^{j}$ & $90^{j}$ & $27.9^{j}$ & $>99^{j}$ & $12.0^{j}$ & $6.1^{j}$ & 0.51 & $205.7^{j}$ & \\
\hline $\begin{array}{l}\mathrm{Fe} / \mathrm{ZSM}- \\
5(2 \mathrm{~N}, 720) \text {-st }\end{array}$ & 3.7 & 37.3 & 94 & 22.9 & 89 & 8.9 & 5.5 & 0.62 & 163.1 & 116 \\
\hline $\begin{array}{l}\mathrm{Fe} / \mathrm{ZSM}- \\
5(4 \mathrm{~N}, 180) \text {-st }\end{array}$ & 11.7 & 54.5 & 91 & 22.0 & 64 & 13.2 & 3.7 & 0.28 & 157.2 & 198 \\
\hline $\begin{array}{l}\mathrm{Fe} / \mathrm{ZSM}- \\
5(4 \mathrm{~N}, 360) \text {-st }\end{array}$ & 6.3 & 50.3 & 86 & 18.6 & 78 & 11.2 & 3.8 & 0.34 & 145.1 & 193 \\
\hline $\begin{array}{l}\mathrm{Fe} / \mathrm{ZSM}- \\
5(4 \mathrm{~N}, 720) \text {-st }\end{array}$ & 4.7 & 40.5 & 89 & 21.4 & $>99$ & 9.0 & 5.3 & 0.56 & 149.6 & 151 \\
\hline
\end{tabular}

${ }^{a}$ Reaction conditions: $1.03 \mathrm{vol} \% \mathrm{Ar}$ and $0.98 \mathrm{vol} \% \mathrm{~N}_{2} \mathrm{O}$ in $\mathrm{He} ; 100 \mathrm{mg}$ catalyst; $T=523 \mathrm{~K} .{ }^{b}$ Reaction conditions: 1.01 vol $\% \mathrm{C}_{6} \mathrm{H}_{6}$ and 4.01 vol \% $\mathrm{N}_{2} \mathrm{O}$ in He; $100 \mathrm{mg}$ catalyst; $T=623 \mathrm{~K}$. ${ }^{c}$ Benzene conversion and selectivity of phenol after 5 min reaction. ${ }^{d}$ Benzene conversion and selectivity of phenol after $24 \mathrm{~h}$ reaction. ${ }^{e}$ Phenol formation rate after 5 min reaction. ${ }^{{ }^{f}}$ Phenol formation rate after $24 \mathrm{~h}$ reaction. ${ }^{g}$ Total amount of phenol after 24 $\mathrm{h}$ reaction per gram of catalyst. ${ }^{h}$ Determined by TGA methods after $24 \mathrm{~h}$ reaction. ${ }^{i}$ After first regeneration by calcination in $\mathrm{O}_{2} / \mathrm{He}$ mixture $(20: 80$ $\mathrm{V} / \mathrm{V}, 100 \mathrm{~mL} \mathrm{~min}^{-1}$ ) at $823 \mathrm{~K}$ for $6 \mathrm{~h} .{ }^{j}$ After second regeneration. 

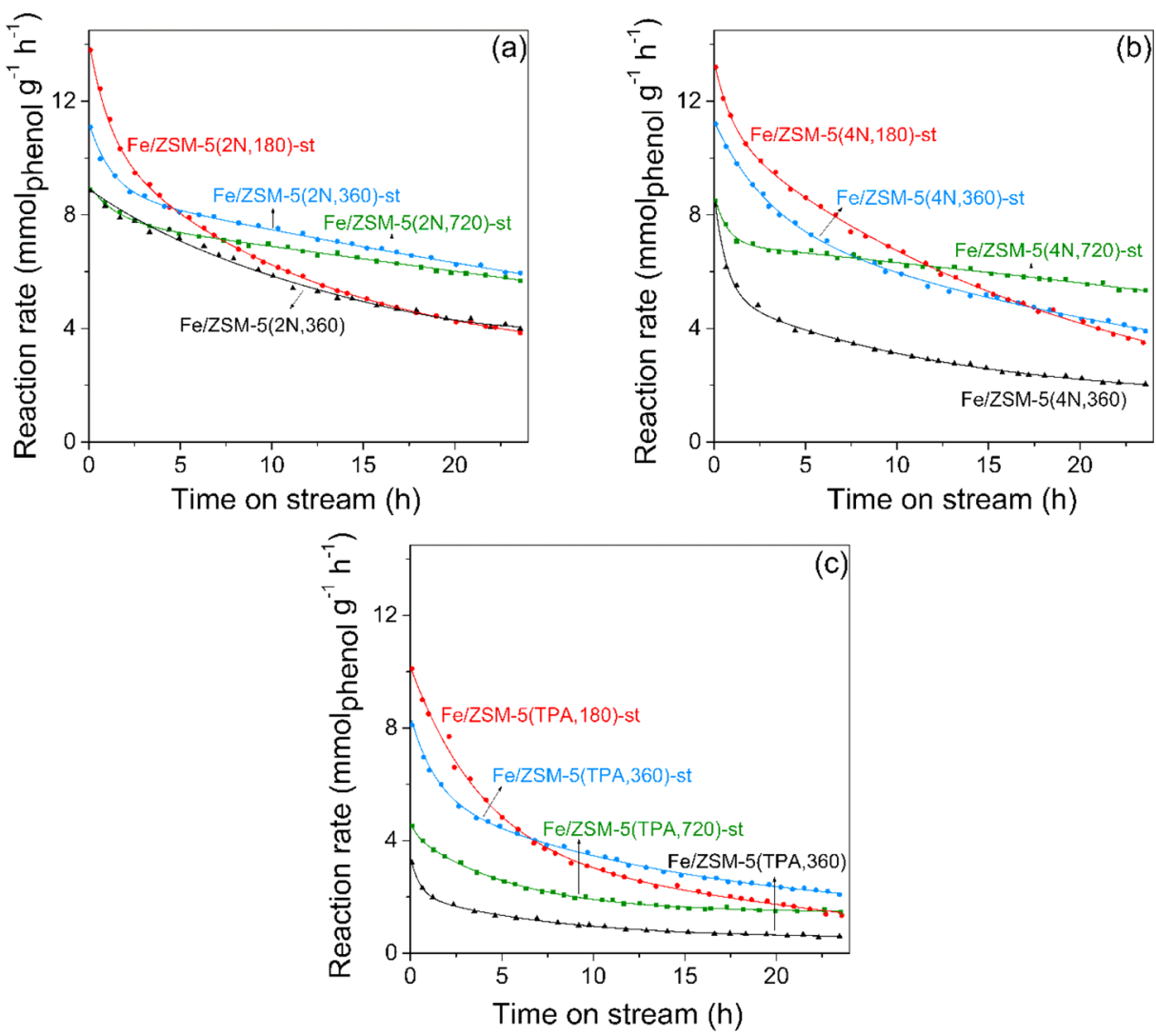

Figure 6. Rate of phenol formation as a function of time on stream for bulk and nanosheet $\mathrm{Fe} / \mathrm{ZSM}-5$ zeolites synthesized by (a) $\mathrm{C}_{22-6-3} \cdot \mathrm{Br}_{2}$, (b) $\mathrm{C}_{22-6-6-6-3} \cdot \mathrm{Br}_{4}$, and (c) TPAOH (reaction conditions: 1.01 vol \% of $\mathrm{C}_{6} \mathrm{H}_{6}$ and 4.01 vol \% of $\mathrm{N}_{2} \mathrm{O}$ in He; $T=623 \mathrm{~K} ; \mathrm{WHSV}=1.89 \mathrm{~g} \mathrm{~g}^{-1} \mathrm{~h}^{-1}$ ).

considered to be the main species to decompose $\mathrm{N}_{2} \mathrm{O}$. Assuming that this reaction is proceeding via a simple chemisorption of one oxygen atom on each active site, the number of " $\alpha$-sites" in catalyst can be determined by measuring the amount of effluent $\mathrm{N}_{2} \cdot{ }^{17,35,38}$ Active site densities determined in this manner are collected in Table 3. Before steaming, zeolite nanosheets contain already more " $\alpha$-sites" than their bulk counterparts. This correlates with the higher amount of extraframework Fe seen in the nanosheet zeolites by DRUV-vis and UV Raman spectroscopy. Steaming leads to higher " $\alpha$-sites" densities in all zeolite samples. This is rationalized by $\mathrm{Fe}^{3+}$ migration from zeolite framework toward extraframework positions. Except for the calcined and steamed Fe/ZSM-5(2N,360) sample, the " $\alpha$-sites" density trends with Fe content. The crystal size of the zeolites does not significantly affect the " $\alpha$-sites" density. The zeolite samples with a $\mathrm{Si} / \mathrm{Fe}$ ratio of 180 contain more than twice the amount of " $\alpha$-sites" than the samples with $\mathrm{Si} / \mathrm{Fe}$ ratio of 720 .

It is important to underline that not all the " $\alpha$-oxygen" sites formed by stoichiometric $\mathrm{N}_{2} \mathrm{O}$ decomposition on " $\alpha$-sites" exhibit the same activity in benzene conversion. It has been noted that only isolated $\mathrm{Fe}^{2+}$ in the $\mathrm{Fe} / \mathrm{ZSM}-5$ extraframework position is effective in catalyzing benzene oxidation to phenol. Oligomeric complexes such as $[\mathrm{Fe}(\mu-\mathrm{O}) \mathrm{Fe}]^{2+}$ and also the ferryl cations $[\mathrm{FeO}]^{+}$result in stable grafted phenolate species upon benzene oxidation. The resulting phenolate complex is so strongly adsorbed that it blocks the Fe sites. The bulky nature of these species results in blockage of the micropores. ${ }^{5,19}$

Catalytic Activity Measurements. The time on stream behavior in the catalytic oxidation of benzene to phenol for various calcined and steamed zeolites is displayed in Figure 6.
The corresponding data are listed in Table 3. As expected, the initial benzene conversion, phenol formation rate, and phenol selectivity (after $5 \mathrm{~min}$ on stream) were substantially higher for the steamed zeolites in comparison to the calcined ones. At the start of the reaction, the reaction rate is mainly determined by the active site density (isolated $\mathrm{Fe}^{2+}$ ). The steamed Fe/ZSM-5 zeolites deactivate more severely than the calcined ones. This is attributed to the higher density of isolated $\mathrm{Fe}^{2+}$ and $\mathrm{Fe}_{x} \mathrm{O}_{y}$ aggregates in the steamed zeolites. As a consequence, the total phenol yield in $24 \mathrm{~h}$ reaction was substantially higher for steamed $\mathrm{Fe} / \mathrm{ZSM}-5$ zeolites than for their calcined counterparts. Despite their greater extent of deactivation, steamed Fe/ ZSM-5 zeolites are preferred as catalysts for the oxidation of benzene to phenol.

The bulk zeolites deactivate more rapidly than the nanosheet zeolite samples. The initial activity of the Fe/ZSM-5 (2N,180)st sample is higher than that of a similar zeolite catalyst using a less-optimal SDA. ${ }^{1}$ For the bulk zeolites, it is seen that both the activity and the extent of deactivation (ratio of reaction rate after $24 \mathrm{~h}$ and initial reaction rate; $R_{24 \mathrm{~h}} / R_{\text {init }}$ ) increase with $\mathrm{Fe}$ content. Among the steamed $2 \mathrm{~N} \mathrm{Fe} / \mathrm{ZSM}-5$ nanosheet samples, the initial benzene conversion and phenol formation rate, the extent of deactivation, and the amount of coke deposited also correlate with $\mathrm{Fe}$ content. There is no clear trend between the phenol selectivity after $5 \mathrm{~min}$ on stream and the Fe content. The bulk zeolites exhibit a lower phenol selectivity, which can be related to secondary reactions due to longer residence time of the desired product in the zeolite crystals. Increasing $\mathrm{Fe}$ content led to higher initial activity, although the differences are less pronounced for the nanostructured zeolite in comparison with the bulk zeolites. 
As mentioned above, not all of the " $\alpha$-sites" are active in the benzene to phenol reaction. Therefore, we do not report turnover frequencies. The higher fraction of inactive " $\alpha$-sites" in bulk Fe/ZSM-5 zeolite relates to formation of more dimeric/ oligomeric $\mathrm{Fe}^{2+}$ species in bulk zeolite. A larger contribution of monomeric $\mathrm{Fe}^{2+}$ in nanosheet samples then explains why variation in $\mathrm{Fe}$ content does not affect the initial activity as much as it does for bulk zeolite. Higher $\mathrm{Fe}$ content in nanosheet zeolites resulted in faster catalyst deactivation. After $24 \mathrm{~h}$ reaction, the phenol formation rate decreased by $78 \%$ for Fe/ZSM-5(2N,180)-st, while only about one-third of the activity of Fe/ZSM-5(2N,720)-st was lost. Consistent with this, zeolite nanosheets with higher Fe content produced more coke.

Figure 7 highlights the trends observed between the density of " $\alpha$-sites", the initial phenol formation rate, and the extent of

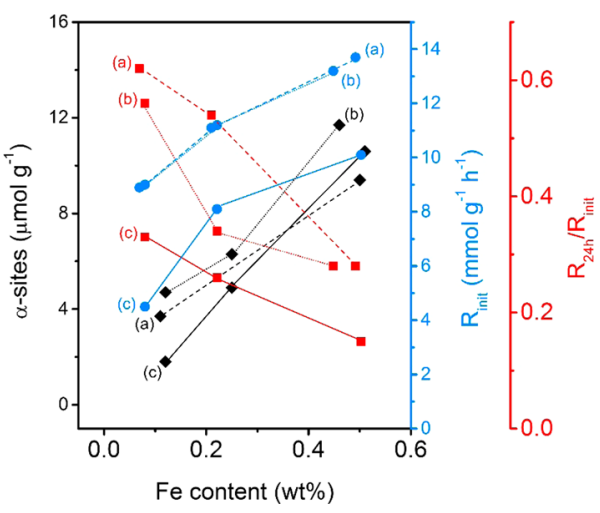

Figure 7. Concentration of " $\alpha$-sites", the phenol formation rate after 5 min time on stream $\left(R_{\text {init }}\right)$, and the ratio of reaction rate after $24 \mathrm{~h}$ and initial reaction rate $\left(R_{24 \mathrm{~h}} / R_{\text {init }}\right)$ at various $\mathrm{Fe}$ contents of steamed $\mathrm{Fe} /$ ZSM-5 catalysts synthesized using (a) $\mathrm{C}_{22-6-3} \cdot \mathrm{Br}_{2}$, (b) $\mathrm{C}_{22-6-6-6-3} \cdot \mathrm{Br}_{4}$, and (c) TPAOH.

deactivation in $24 \mathrm{~h}$ with the Fe content of the zeolites. Higher Fe content leads to a higher density of " $\alpha$-sites", regardless of the crystal size. The " $\alpha$-sites" density of the sample prepared at intermediate Fe content with $\mathrm{C}_{22-6-3} \mathrm{Br}_{2}$ is an outlier. The higher Fe content also results in a higher initial phenol formation rate. The nanosheet samples display a higher rate than the bulk samples. At the same time, the extent of deactivation trends oppositely with the Fe content. That is to say, the nanosheet samples deactivate less severely than the bulk zeolite with the lowest extent of deactivation observed for the thinnest nanosheets at the lowest Fe content.

We estimated whether mass transport can limit the reaction rate of the benzene to phenol reaction. We used the WeiszPrater criterion, as the detailed kinetics of benzene oxidation by nitrous oxide are unknown:\#tab;

$$
\phi=\frac{L^{2} r_{v, \text { obs }}}{D_{\text {eff }} \times C_{\text {surface }}}<0.15
$$

Ignoring external mass transfer by setting the surface benzene concentration to the bulk gas-phase value of $C_{\text {surface }}=0.2 \mathrm{~mol}$ $\mathrm{m}^{-3}$, using the bulk density of ZSM-5 $\left(0.72 \mathrm{~g} \mathrm{~mL}^{-1}\right)$ to convert initial reaction rates to volumetric rates, $L_{\text {bulk zeolite }}=200 \mathrm{~nm}$, $L_{\text {nanosheet }}=1 \mathrm{~nm}, D_{\text {eff }}=10^{-13} \mathrm{~m}^{2} \mathrm{~s}^{-1}$ for benzene and assuming the reaction order as 1 , we find $\Phi_{\text {bulk zeolite }} \approx 4$ and $\Phi_{\text {nanosheet }} \approx$ $10^{-4}$. As we expect that phenol diffuses slightly slower through the zeolite channels than benzene, we conclude that the reaction rate is limited by the mass transport of benzene in the bulk zeolite, but not in the nanosheet zeolite. This difference contributes to the higher initial rates observed for the zeolite nanosheet samples. We did not observe a strong correlation between the " $\alpha$-site" densities and the initial reaction rate for the nanosheet samples. The main reason for this should be that not all " $\alpha$-sites" are involved in the benzene oxidation reaction, as discussed in the Introduction.

Figure 8 discusses schematically the decreasing probability of $\mathrm{Fe}$ agglomeration sites in the channels as a function of $\mathrm{Fe}$

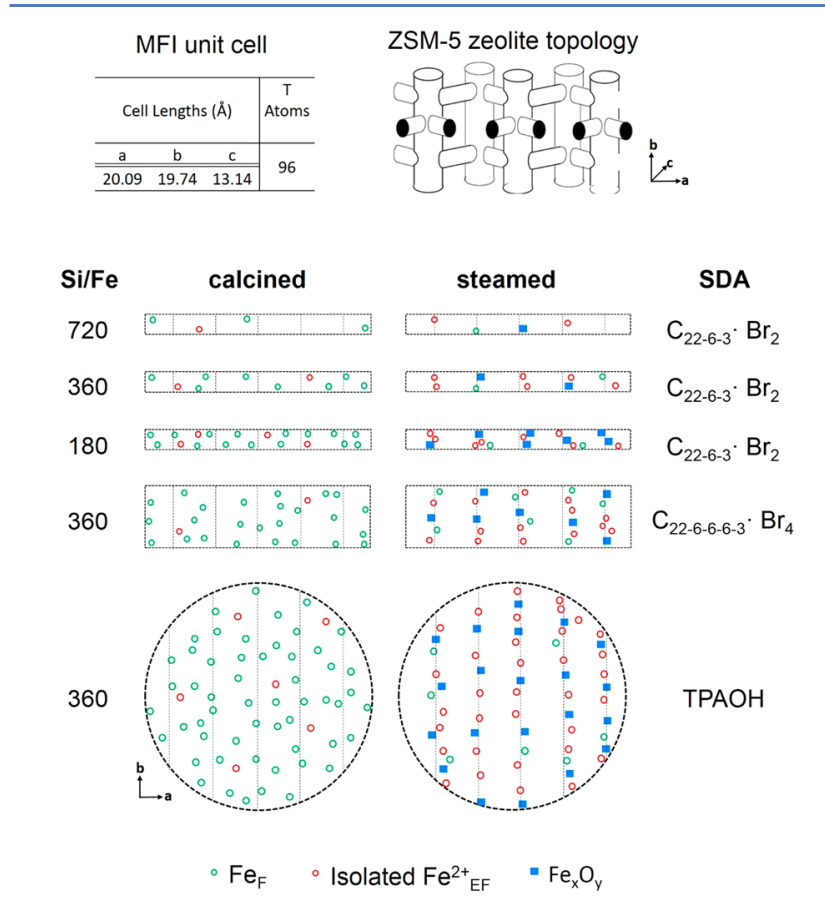

Figure 8. Schematic illustration of influence of Fe content and zeolite domain size for calcined and steamed Fe/ZSM-5 zeolite.

content. Each MFI unit cell contains 2 straight channels and 96 $\mathrm{T}$ atoms. For the thinnest Fe/ZSM-5 nanosheet zeolite, the number of $\mathrm{T}$ atoms amounts to approximately 72 per straight channel. Thus, a benzene molecule diffusing through Fe/ZSM5 nanosheet zeolite with a $\mathrm{Si} / \mathrm{Fe}$ ratio of 360 will encounter on average much less than $1 \mathrm{Fe}$ site. This limits the contribution of secondary reactions of phenol as compared to bulk zeolite. Deactivation is lowered when the $\mathrm{Fe}$ content of the nanosheet zeolite is lowered to $\mathrm{Si} / \mathrm{Fe}=720$. Nevertheless, coking deactivation will still occur in the nanosheet zeolites. With decreasing Fe content, the extent of deactivation decreases, and the value of $R_{24 \mathrm{~h}} / R_{\text {init }}$ levels off at $\sim 0.6$. In comparison, secondary reactions play a more important role in bulk zeolite, explaining the greater extent of deactivation. Even for $\mathrm{Si} / \mathrm{Fe}=$ $720, R_{24 h} / R_{\text {init }}$ is 0.33 for bulk zeolite. The overall coke content for the bulk zeolites is lower than for the nanosheet samples, which we attribute to the lower utilization degree of the micropore space. That is to say that the mass transfer limitations in the bulk zeolite limit the reaction zone of the zeolite crystal. As the carbonaceous deposits are large, benzene cannot reach the inner parts of the zeolite anymore. This is the most important cause of the lower phenol yield for the bulk zeolites. The thicker Fe/ZSM-5 zeolite nanosheets synthesized with $\mathrm{C}_{22-6-6-6-3} \cdot \mathrm{Br}_{4}$ behave in a similar manner with slightly lower performance as compared with the $2 \mathrm{~N}$ samples. 
Overall, the highest catalytic performance was observed for $\mathrm{Fe} / \mathrm{ZSM}-5(2 \mathrm{~N}, 360)$-st with a thickness of $3 \mathrm{~nm}$ and on average $0.2 \mathrm{Fe}$ sites per pass through the straight channels. The phenol productivity was $185 \mathrm{mmol} \mathrm{g}^{-1}$, and the zeolite retained more than half of its initial activity after $24 \mathrm{~h}$. The reusability of this catalyst was assessed in three reaction-regeneration cycles. No significant decrease in its catalytic performance in these experiments was observed, and phenol productivities remained around $180-200 \mathrm{mmol} \mathrm{g}^{-1}$ after intermittent air calcination at $823 \mathrm{~K}$ to burn off the coke.

The textural properties of the spent catalysts were also investigated by Ar physisorption measurements (Figure 9). The
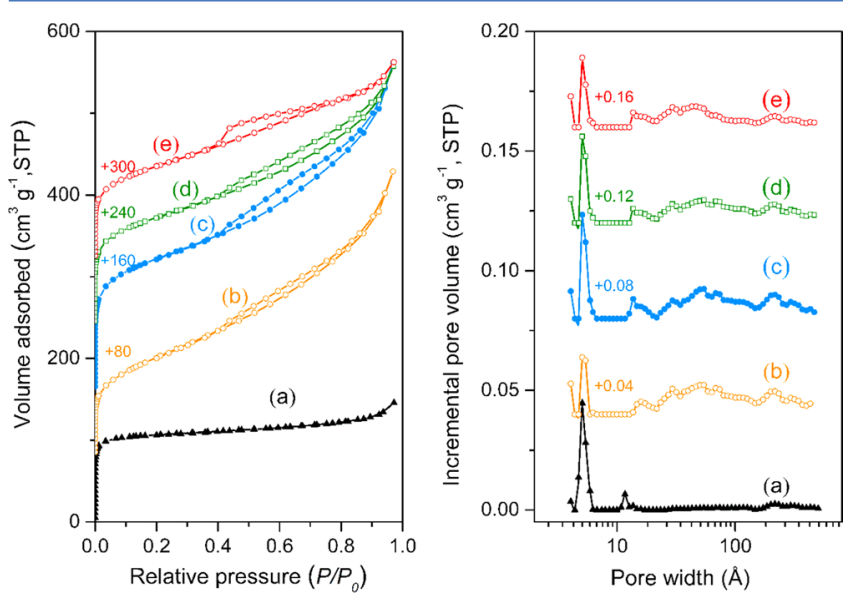

Figure 9. Ar physisorption isotherms (left) and pore size distribution (right) of spent zeolites. (a) Fe/ZSM-5(TPA,360)-st, (b) Fe/ZSM5(2N,180)-st, (c) Fe/ZSM-5(2N,360)-st, (d) Fe/ZSM-5(2N,720)-st, and (e) Fe/ZSM-5 $(4 \mathrm{~N}, 360)$-st. The isotherms were vertically offset by equal intervals of $80 \mathrm{~cm}^{3} \mathrm{~g}^{-1}$. The pore size distributions were calculated via NLDFT method using the adsorption branch and vertically offset by equal intervals of $0.04 \mathrm{~cm}^{3} \mathrm{~g}^{-1}$.

corresponding numerical data are collected in Table 4. The isotherm of spent Fe/ZSM-5(TPA,360)-st has the same characteristic type I shape as the fresh zeolite. Although the isotherms of spent $\mathrm{Fe} / \mathrm{ZSM}-5$ zeolite nanosheets are still of type IV, the area of the hysteresis loop is significantly smaller than for the fresh zeolites. This is because part of the mesopores in the spent catalysts are blocked by coke deposits. The pore size distribution of the spent samples confirms the lowered mesopore volume. The data in Table 4 illustrate that, compared with the fresh samples, all of the spent samples have a lower BET surface area and total pore volume. The decrease of the total pore volume is much more pronounced for the $\mathrm{Fe} /$ ZSM-5 zeolite nanosheets than for the bulk zeolites. One reason could be that, compared with bulk Fe/ZSM-5 zeolites, the small size along the $b$-direction of zeolite nanosheets facilitates mass transport, which leads to more efficient utilization of the micropore space. This contributes to a higher activity of nanosheet zeolites, as discussed above. The higher utilization degree of the crystal also leads to a higher amount of coke deposited. Deactivation due to plugging of pores in naosheet zeolites by carbonaceous deposits is much less pronounced for the nanosheet zeolites, because of the much higher surface to bulk ratio. Notably, increasing thickness of $\mathrm{Fe} / \mathrm{ZSM}-5$ zeolite nanosheets in $b$-direction results in a stronger decrease of the pore volume during the oxidation reaction. This is in accordance with the difference in catalytic performance after $24 \mathrm{~h}$ reaction. Textural characterization of the spent nanosheet zeolites shows that carbonaceous coke was mainly deposited in the mesopores in nanosheet zeolites. In comparison with spent bulk zeolite, the micropore volume was less affected. This may be explained by the shorter diffusion pathways of coke or coke precursors to reach the external surface of the nanosheet zeolites. As diffusion distances to the external surface of bulk zeolite are much longer, coke will be mostly deposited in the micropores.

Panov and co-workers found that catalyst deactivation due to coking could be significantly decreased by operating the benzene oxidation reaction at a high $\mathrm{C}_{6} \mathrm{H}_{6} / \mathrm{N}_{2} \mathrm{O}$ ratio, i.e., in excess benzene. ${ }^{6,39} \mathrm{We}$ also investigated catalyst performance at a $\mathrm{C}_{6} \mathrm{H}_{6} / \mathrm{N}_{2} \mathrm{O}$ ratio of 10 for the best performing Fe/ZSM-5 nanosheet zeolite (Fe/ZSM-5 (2N, 360)-st) and its bulk counterpart (Fe/ZSM-5(TPA, 360)-st) at a reaction temperature of $643 \mathrm{~K}$. The time on stream plots is shown in Figure 10, and the corresponding catalytic performance data are listed in Table S1. Notably, the $\mathrm{N}_{2} \mathrm{O}$ selectivity was close to $100 \%$, indicating that phenol was the major product, i.e., overoxidation to dihydroxybenzenes is limited under these conditions. We surmise that the high concentration of benzene lowers the rate of consecutive oxidation of benzene, suppressing the formation of heavy byproducts that can deactivate the catalyst. Similar to the reports of Panov, ${ }^{6,39}$ catalyst deactivation is much less pronounced in excess benzene. The initial catalytic activity of the nanosheet zeolite is about $50 \%$ higher than that of the bulk zeolite. We attribute the lower performance of the bulk zeolite to mass transport limitations. In accordance with this, we found that the amount of coke formed on the bulk zeolite under these conditions is lower than on the nanosheet zeolite (Table S1). This is due to a smaller fraction of the micropore space being involved in the benzene oxidation reaction.

Table 4. Composition and Textural Properties of Spent Fe/ZSM-5 Catalysts After 24 h Reaction in Benzene Oxidation

\begin{tabular}{lccccccc}
\multicolumn{1}{c}{ catalyst } & $S_{\text {BET }}{ }^{a}\left(\mathrm{~m}^{2} \mathrm{~g}^{-1}\right)$ & $V_{\text {total }}{ }^{b}\left(\mathrm{~cm}^{3} \mathrm{~g}^{-1}\right)$ & $V_{\text {meso }}{ }^{c}\left(\mathrm{~cm}^{3} \mathrm{~g}^{-1}\right)$ & $V_{\text {supermicro }}{ }^{d}\left(\mathrm{~cm}^{3} \mathrm{~g}^{-1}\right)$ & $V_{\text {micro }}{ }^{e}\left(\mathrm{~cm}^{3} \mathrm{~g}^{-1}\right)$ & $V_{\text {meso }} / V_{\text {meso,0 }}$ & $V_{\text {micro }} / V_{\text {micro, } 0}$ \\
Fe/ZSM-5 (2N,180)-st & 350 & 0.41 & 0.31 & 0.000 & 0.08 & 0.86 \\
Fe/ZSM-5 (2N,360)-st & 453 & 0.47 & 0.33 & 0.003 & 0.17 & 0.82 \\
Fe/ZSM-5 (2N,720)-st & 372 & 0.37 & 0.25 & 0.000 & 0.14 & 0.76 \\
Fe/ZSM-5 (4N,360)-st & 326 & 0.28 & 0.18 & 0.008 & 0.12 & 0.40 \\
Fe/ZSM-5 (TPA,360)-st & 284 & 0.17 & 0.04 & 0.007 & 0.10 & 0.93 \\
\end{tabular}

${ }^{a} \mathrm{BET}$ surface area $\left(p / p_{0}=0.05-0.25\right) .{ }^{b}$ Total pore volume at relative pressure $p / p_{0}=0.97 .{ }^{c}$ Mesopore volume calculated by the NLDFT method using the adsorption branch of the isotherm. ${ }^{d}$ Supermicropore volume defined as pores in the range $1.0-2.0 \mathrm{~nm}$, determined by the NLDFT method. ${ }^{e}$ Micropore volume of bulk Fe/ZSM-5 was determined by $t$-plot method via the Broekhoff-de Boer model in the thickness range of $0.34-$ $0.50 \mathrm{~nm}$. Micropore $(<1.0 \mathrm{~nm})$ volume of sheet Fe/ZSM-5 was determined by the NLDFT method. 


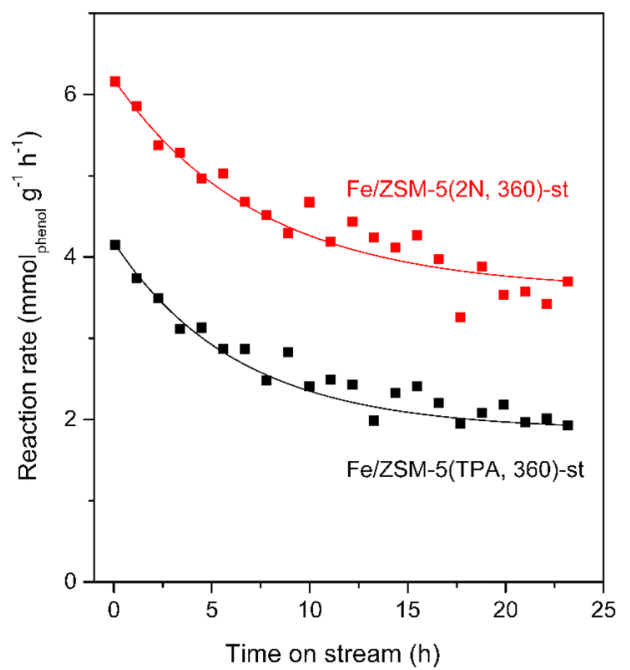

Figure 10. Rates of phenol formation as a function of time on stream for bulk and nanosheet Fe/ZSM-5 zeolites (reaction conditions: 5 vol $\% \mathrm{C}_{6} \mathrm{H}_{6}$ and 0.5 vol \% $\mathrm{N}_{2} \mathrm{O}$ in $\mathrm{He}$; $T=643 \mathrm{~K}$; WHSV $=9.45 \mathrm{~g} \mathrm{~g}^{-1}$ $\left.\mathrm{h}^{-1}\right)$.

\section{CONCLUSIONS}

A set of $\mathrm{Fe} / \mathrm{ZSM}-5$ zeolite nanosheets with thicknesses of $\sim 3$ $\mathrm{nm}$ and $\sim 6-8 \mathrm{~nm}$ and with varying $\mathrm{Fe}$ content were synthesized, extensively characterized, and compared to bulk $\mathrm{Fe} / \mathrm{ZSM}-5$ zeolite in the oxidation of benzene to phenol with nitrous oxide. In all cases, steaming is effective in increasing the number of active $\mathrm{Fe}^{2+}$ centers for $\mathrm{N}_{2} \mathrm{O}$ decomposition and benzene oxidation. The degree of $\mathrm{Fe}$ aggregation during steaming increases with the Fe content and the crystal domain size. These two parameters also strongly affected the catalytic performance. Decreasing the number of active centers along the $b$-direction of the zeolite crystals strongly suppresses secondary reactions of phenol and, accordingly, the extent of deactivation. This together with the absence of diffusional limitations in nanosheet zeolites explains the much higher phenol yield that can be obtained with nanostructured Fe/ZSM-5. The steamed $\mathrm{Fe} / \mathrm{ZSM}-5$ zeolite nanosheet synthesized using $\mathrm{C}_{22-6-3} \cdot \mathrm{Br}_{2}$ (domain size in $b$-direction $\sim 3 \mathrm{~nm}$ ) and containing $0.24 \mathrm{wt}$ $\% \mathrm{Fe}$ exhibited the highest catalytic performance. During the first $24 \mathrm{~h}$ on stream, this catalyst produced $185 \mathrm{mmol}_{\text {phenol }} \mathrm{g}^{-1}$. Calcination to remove the coke deposits completely restores the initial activity. The optimized catalyst retains its improved activity and stability during benzene oxidation at a high benzene-to-nitrous oxide ratio.

\section{ASSOCIATED CONTENT}

\section{S Supporting Information}

The Supporting Information is available free of charge on the ACS Publications website at DOI: 10.1021/acscatal.6b03512.

Detailed information regarding $\mathrm{XRD}, \mathrm{Ar}$ physisorption, and catalytic performance data at a high $\mathrm{C}_{6} \mathrm{H}_{6} / \mathrm{N}_{2} \mathrm{O}$ ratio (PDF)

\section{AUTHOR INFORMATION}

\section{Corresponding Author}

*E-mail: e.j.m.hensen@tue.nl.

ORCID $\odot$

Emiel J. M. Hensen: 0000-0002-9754-2417

\section{Present Address}

"State Key Laboratory of Heavy Oil Processing, The Key Laboratory of Catalysis of CNPC, College of Chemical Engineering, China University of Petroleum, No. 18 Fuxue Road, Changping, Beijing 102249, China.

Notes

The authors declare no competing financial interest.

\section{ACKNOWLEDGMENTS}

The authors would like to thank the China Scholarship Council for financial support, A.M. Elemans-Mehring for ICP-OES analysis, and the Soft Matter Cryo-TEM Research Unit of Eindhoven University of Technology for access to TEM facilities. E.J.M.H. acknowledges support from a TOP grant of the Chemical Sciences division of The Netherlands Organization for Scientific Research.

\section{REFERENCES}

(1) Koekkoek, A. J. J.; Kim, W.; Degirmenci, V.; Xin, H.; Ryoo, R.; Hensen, E. J. M. J. Catal. 2013, 299, 81-89.

(2) Balducci, L.; Bianchi, D.; Bortolo, R.; D’Aloisio, R.; Ricci, M.; Tassinari, R.; Ungarelli, R. Angew. Chem. 2003, 115, 5087-5090.

(3) Neidig, M. L.; Hirsekorn, K. F. Catal. Commun. 2011, 12, 480484.

(4) Abu-Zied, B. M.; Schwieger, W.; Unger, A. Appl. Catal., B 2008, 84, 277-288.

(5) Jia, J.; Pillai, K. S.; Sachtler, W. M. H. J. Catal. 2004, 221, 119126.

(6) Pirutko, L. V.; Chernyavsky, V. S.; Uriarte, A. K.; Panov, G. I. Appl. Catal., A 2002, 227, 143-157.

(7) Choi, J. S.; Kim, T. H.; Choo, K. Y.; Sung, J. S.; Saidutta, M. B.; Ryu, S. O.; Song, S. D.; Ramachandra, B.; Rhee, Y. W. Appl. Catal., A 2005, 290, 1-8.

(8) Panov, G. I.; Sheveleva, G. A.; Kharitonov, A. S.; Romannikov, V. N.; Vostrikova, L. A. Appl. Catal., A 1992, 82, 31-36.

(9) Dubkov, K. A.; Ovanesyan, N. S.; Shteinman, A. A.; Starokon, E. V.; Panov, G. I. J. Catal. 2002, 207, 341-352.

(10) Panov, G. I. CATTECH 2000, 4, 18-31.

(11) Gaidei, T. P. Russ. J. Appl. Chem. 2009, 82, 1689-1705.

(12) Zecchina, A.; Rivallan, M.; Berlier, G.; Lamberti, C.; Ricchiardi, G. Phys. Chem. Chem. Phys. 2007, 9, 3483-3499.

(13) Hensen, E. J. M.; Zhu, Q.; Hendrix, M. M. R. M.; Overweg, A. R.; Kooyman, P. J.; Sychev, M. V.; van Santen, R. A. J. Catal. 2004, 221, 560-574.

(14) Hensen, E. J. M.; Zhu, Q.; van Santen, R. A. J. Catal. 2003, 220, 260-264.

(15) Chernyavsky, V. S.; Pirutko, L. V.; Uriarte, A. K.; Kharitonov, A. S.; Panov, G. I. J. Catal. 2007, 245, 466-469.

(16) Moretti, G.; Fierro, G.; Ferraris, G.; Andreozzi, G. B.; Naticchioni, V. J. Catal. 2014, 318, 1-13.

(17) Kiwi-Minsker, L.; Bulushev, D. A.; Renken, A. J. Catal. 2003, 219, 273-285.

(18) Hensen, E. J. M.; Zhu, Q.; Janssen, R. A. J.; Magusin, P. C. M. M.; Kooyman, P. J.; van Santen, R. A. J. Catal. 2005, 233, 123-135.

(19) Li, G.; Pidko, E. A.; van Santen, R. A.; Feng, Z.; Li, C.; Hensen, E. J. M. J. Catal. 2011, 284, 194-206.

(20) Ivanov, D. P.; Pirutko, L. V.; Panov, G. I. J. Catal. 2014, 311, 424-432.

(21) W cław, A.; Nowińska, K.; Schwieger, W. Appl. Catal., A 2004, $270,151-156$.

(22) Meloni, D.; Monaci, R.; Solinas, V.; Berlier, G.; Bordiga, S.; Rossetti, I.; Oliva, C.; Forni, L. J. Catal. 2003, 214, 169-178.

(23) Zhu, Q.; van Teeffelen, R. M.; van Santen, R. A.; Hensen, E. J. M. J. Catal. 2004, 221, 575-583.

(24) Jiang, J.; Yu, J.; Corma, A. Angew. Chem., Int. Ed. 2010, 49, $3120-3145$ 
(25) Na, K.; Choi, M.; Ryoo, R. Microporous Mesoporous Mater. 2013, $166,3-19$.

(26) Xin, H.; Koekkoek, A.; Yang, Q.; van Santen, R.; Li, C.; Hensen, E. J. M. Chem. Commun. 2009, 7590-7592.

(27) Koekkoek, A. J. J.; Xin, H.; Yang, Q.; Li, C.; Hensen, E. J. M. Microporous Mesoporous Mater. 2011, 145, 172-181.

(28) Choi, M.; Na, K.; Kim, J.; Sakamoto, Y.; Terasaki, O.; Ryoo, R. Nature 2009, 461, 246-249.

(29) Na, K.; Jo, C.; Kim, J.; Cho, K.; Jung, J.; Seo, Y.; Messinger, R. J.; Chmelka, B. F.; Ryoo, R. Science 2011, 333, 328-32.

(30) Park, W.; Yu, D.; Na, K.; Kim, E. J.; Slater, B.; Sakamoto, Y.; Ryoo, R. Chem. Mater. 2011, 23, 5131-5137.

(31) Zhu, X.; Goesten, M. G.; Koekkoek, A. J. J.; Mezari, B.; Kosinov, N.; Filonenko, G.; Friedrich, H.; Rohling, R.; Szyja, B. M.; Gascon, J.; Kapteijn, F.; Hensen, E. J. M. Chem. Sci. 2016, 7, 6506-6513.

(32) Ribera, A.; Arends, I. W. C. E.; de Vries, S.; Pérez-Ramírez, J.; Sheldon, R. A. J. Catal. 2000, 195, 287-297.

(33) Xia, H.; Sun, K.; Sun, K.; Feng, Z.; Li, W. X.; Li, C. J. Phys. Chem. C 2008, 112, 9001-9005.

(34) Fan, F.; Sun, K.; Feng, Z.; Xia, H.; Han, B.; Lian, Y.; Ying, P.; Li, C. Chem. - Eur. J. 2009, 15, 3268-3276.

(35) Xia, H.; Sun, K.; Fan, F.; Sun, K.; Su, W.; Feng, Z.; Ying, P.; Li, C. J. Catal. 2008, 259, 269-275.

(36) Wu, L.; Magusin, P. C. M. M.; Degirmenci, V.; Li, M.; Almutairi, S. M. T.; Zhu, X.; Mezari, B.; Hensen, E. J. M. Microporous Mesoporous Mater. 2014, 189, 144-157.

(37) Zhu, X.; Wu, L.; Magusin, P. C. M. M.; Mezari, B.; Hensen, E. J. M. J. Catal. 2015, 327, 10-21.

(38) Sun, K.; Zhang, H.; Xia, H.; Lian, Y.; Li, Y.; Feng, Z.; Ying, P.; Li, C. Chem. Commun. 2004, 2480-2481.

(39) Ivanov, A. A.; Chernyavsky, V. S.; Gross, M. J.; Kharitonov, A. S.; Uriarte, A. K.; Panov, G. I. Appl. Catal., A 2003, 249, 327-343. 